\title{
العواهل المؤثرة على الإنتاج في صناعة الملابس الجاهزة بمدينة جدة
}

\author{
إعداد \\ د. نور عبد الهاديل الصبيا نحسـ \\ جامعة أم القرى- مكة المكرمة \\ كلية التربية
}

مجلة بحوث التربية النوعية - جامعة المنصورة

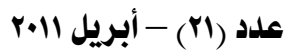




\title{
العواهل المؤثرة على الإنتاج في صناعة الملابس الجاهزة بمدينة جدة
}

\author{
إعداد \\ د . نور عبد الهاديالصبياني
}

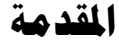

برزت أهمية دراسة الإنتاجية وتحسينها يِّ الدول الصناعية بشكل عام والدول الناميـة بشكل

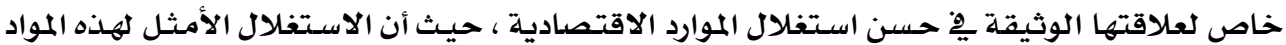

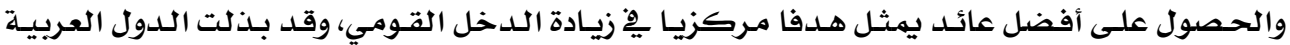

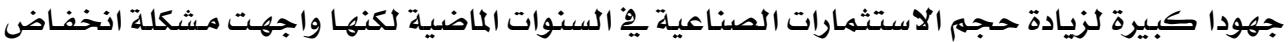

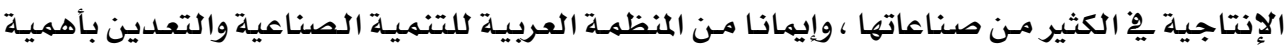

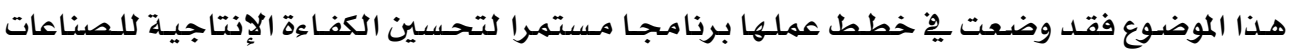

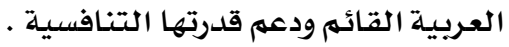
ويعتبر الإنتـاج مـن الموضـوعات الحيويـة الـتي تهـدف إلى خفضـ التكـاليف ، وزيــادة القـــرة التنافسية للصادرات. (محمد كامل : 199V م: IV) .

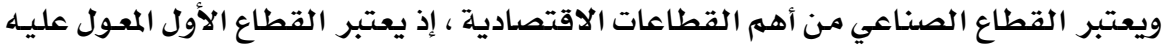

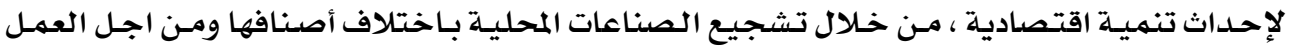

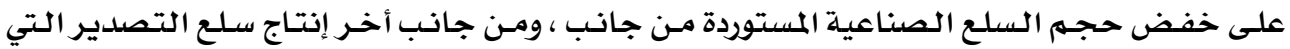

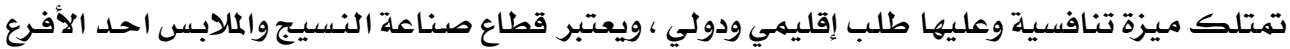

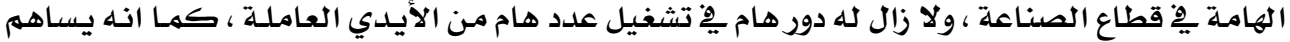

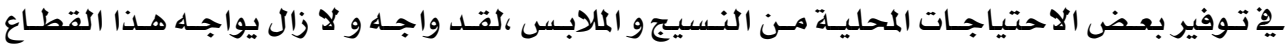
تحديات كبيرة .

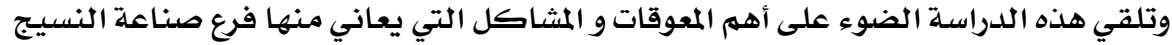

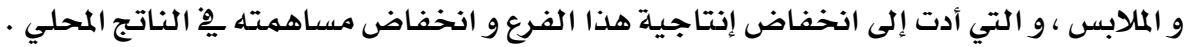

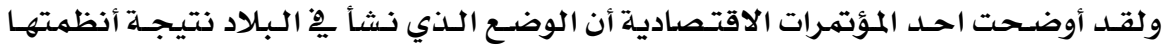

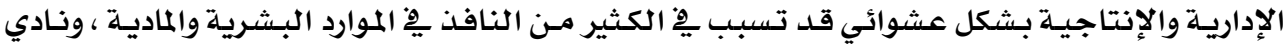

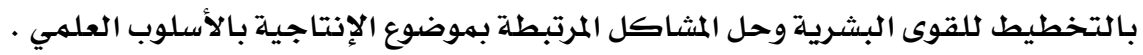

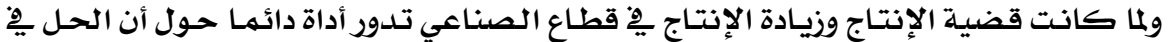

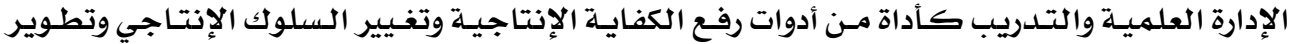

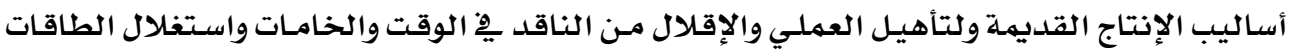


العاملة وتغيير قوانين العمل الحالية ، ومن جهة أخرى تعديل السياسة النقديـة والسعرية والانتمائيـة

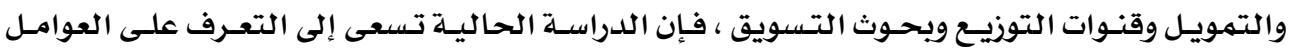

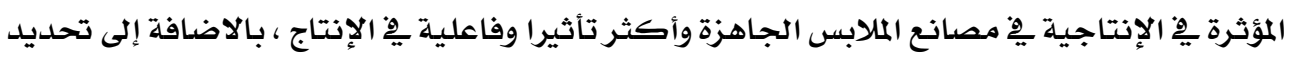

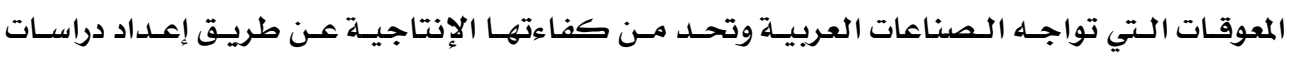

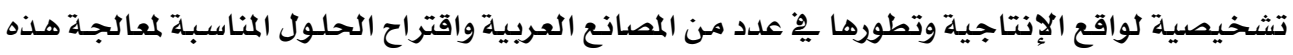

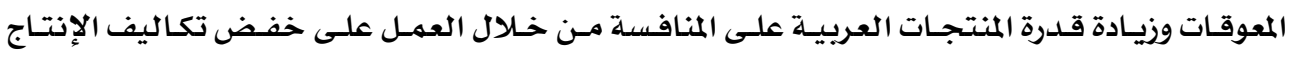

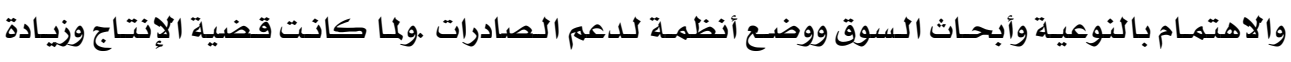

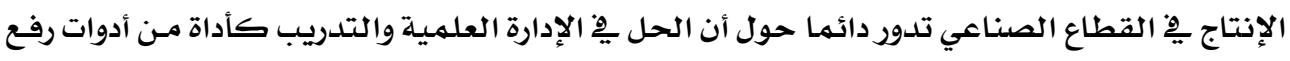

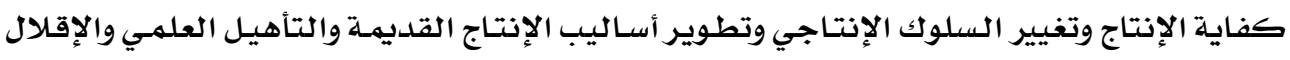

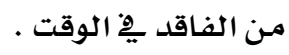

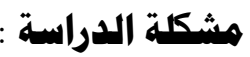

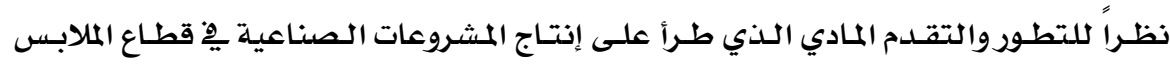

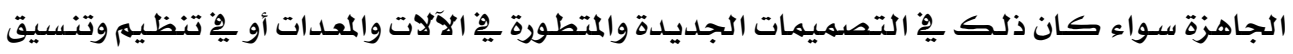

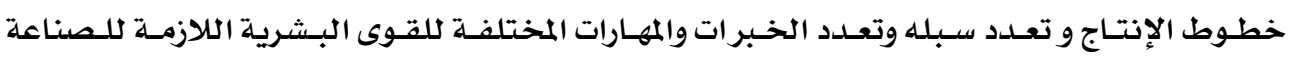

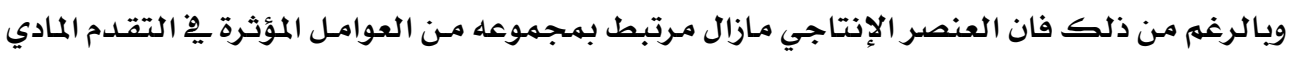

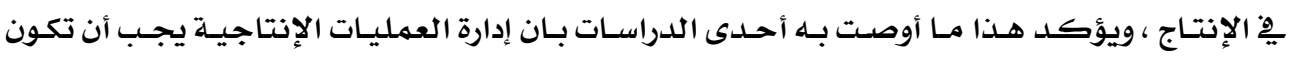

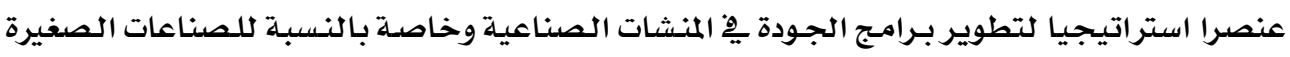

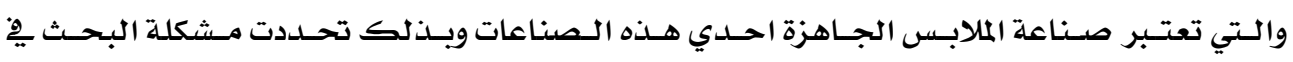

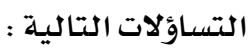

ما الخصائص السيكومترية لمقياس العوامل المؤثرة ِِِ أنتاج الملابس الجاهزة ؟

$$
\begin{aligned}
& \text { ويتفرع من هذا السؤال التساؤلات التالية : } \\
& \text { أ - مـا خصائص مفردات العينة ؟ } \\
& \text { ب- ما قيم ودلالة مؤشرات الثبات ؟ } \\
& \text { ج- ما قيم ودلالة مؤشرات الصدق ؟ }
\end{aligned}
$$

الأهداف الدراسة :

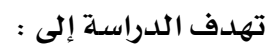

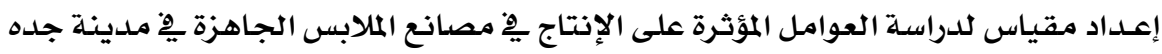

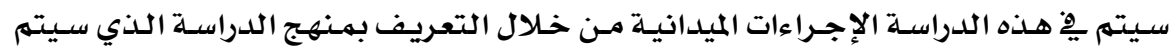

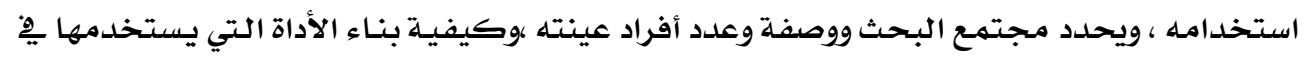


هـذه الدراسـة ، والتحقـق مـن صسـقها وثباتها وتحديـد المعالجـات الإحـصائية المناسـبـة لتحليـل بيانـات الدراسـة .

\section{هنهج الدراسة :}

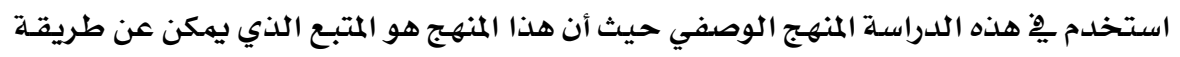

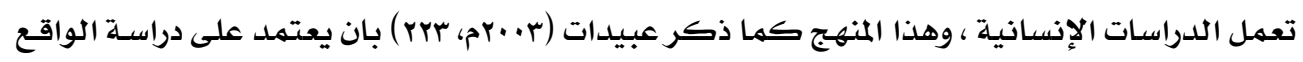

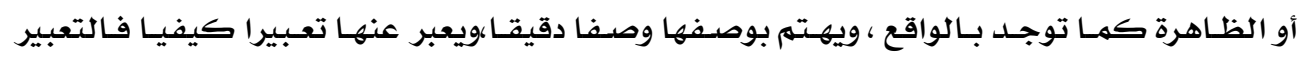

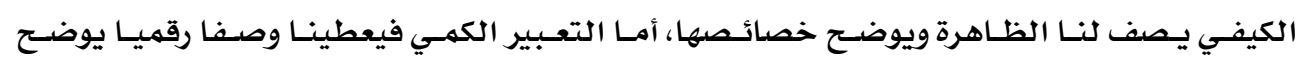

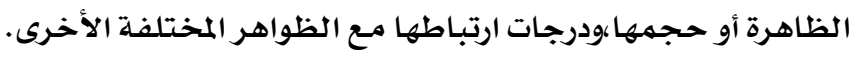
واختارت الباحثة الأسلوب الوصفي لأنه يمثل الأسلوب الأمثل لجمــع البيانـات مـن مصدادرها

الأولية.

ومسن خلال هذا المنهج نستطيع إجـراء الدراسـة "العوامل المؤثرة على الإنتاج جِّه مـصانع جـده

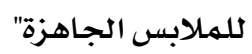

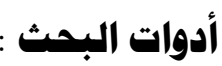

الاستبانة :

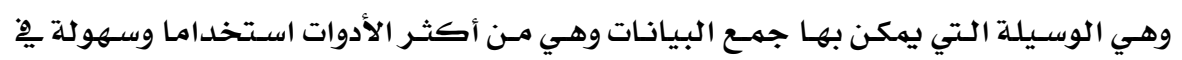

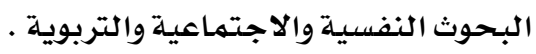

وصف العينة :

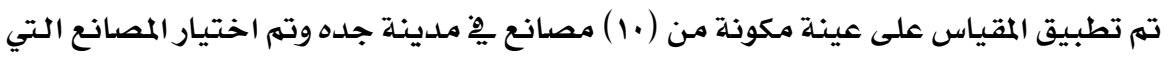

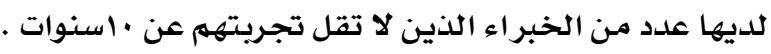

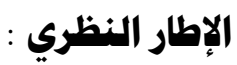

• صناعة ملابس الجاهزة :

تعددت تعريفات التصنيع ، فنجد أن هناك أراء تعتبر التصنيع مجرد أقامة الصناعة ، كهـا

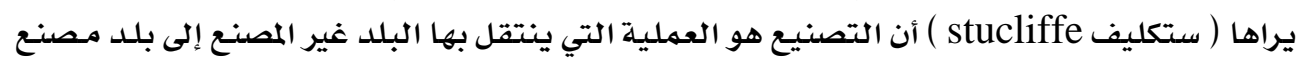

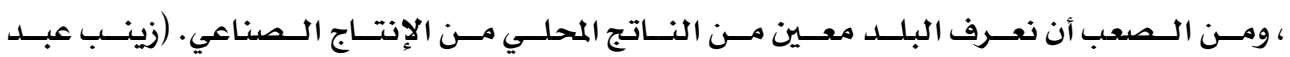

الحفيظ:(r... (r).

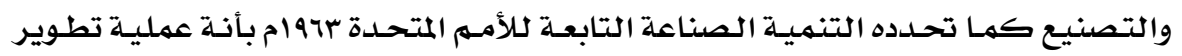

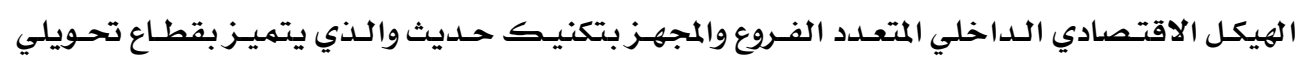

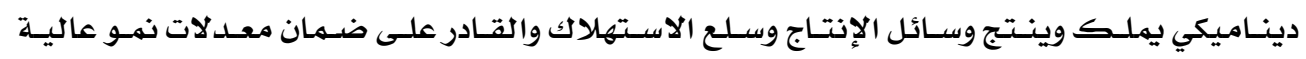

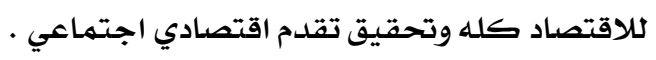


بينما هذه التعريفات ركزت على الجانب الاقتصادي للتصنيع فان هنـاك مـن الآراء الأخـرى

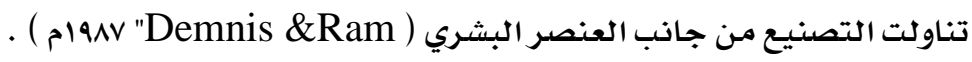

أن التصنيع هو عملية يتهم من خلالها الاستغلال الأمثل للقوى العاملة يِّ إنتاج المواد الخـام

$$
\text { والمنتجات والخدمات . }
$$

ومما سبق يتضح أن التصنيع هو احد عناصر عملية التنمية الاقتصادية والاجتماعية كما

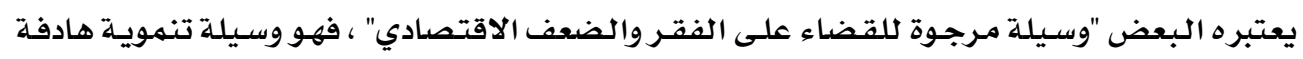

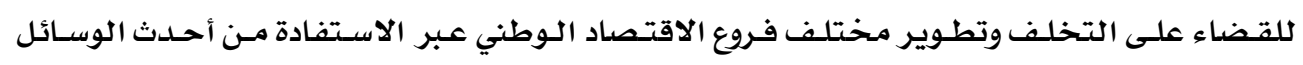
التكنولوجية يف شتى الميادين الإنتاجية.

$$
\text { ويقصد بتصنيع الملابس الجاهزة : ولمين }
$$

هـو عمليـة اسـتغلال القـوى البشرية العاملـة "عمـال"الاستغلال الأمثل لتشغيل الماكينـات

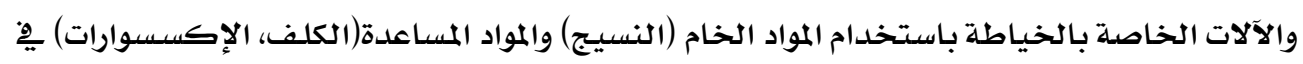

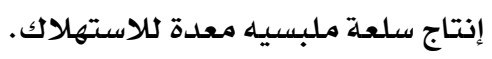

\section{• الصناعة :}

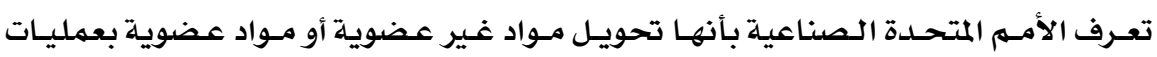

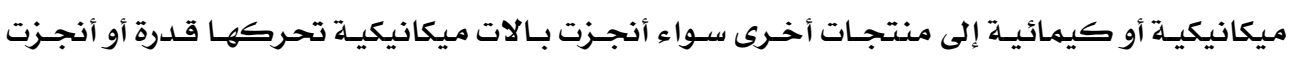

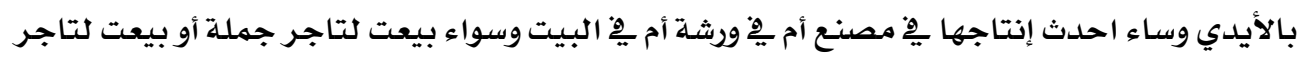

تجزئية.

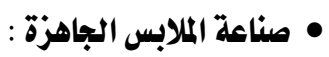

وهي العمليات التي تمر بها الخامـات المعدة للانتاج منذ أن كانت أقمشة حتى تصبح قطعـة

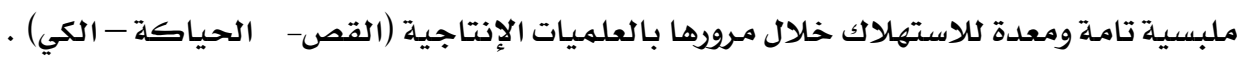

• تنمية الصناعة :

ويقصد بها التوسع الصناعي باقامـة المشروعات الصناعية الجديده ، او التوسع عِ إلمثروعات

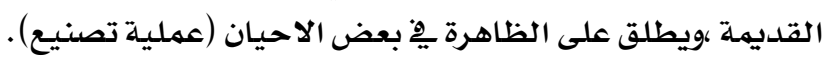

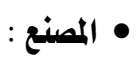

يعرف المصنع المعجم الوسيط انه هو الموضـع الذذي تهـارس فيـه صسناعة أو صنـاعات مختلفـة

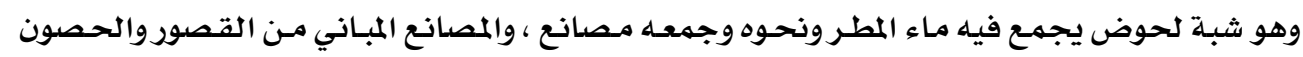

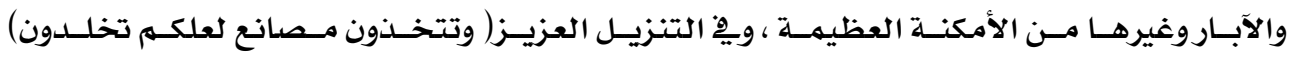

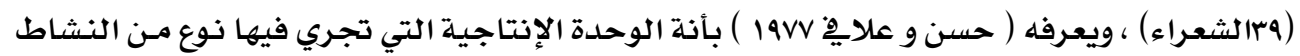
الإنتاجي بغرض خلق سلعة تنتج طبقا لخصائص معينة. 


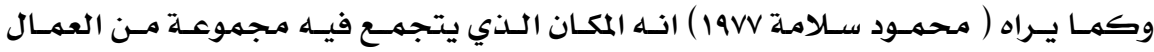

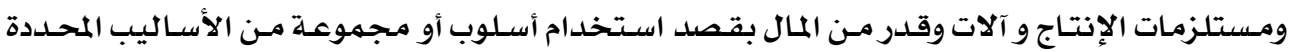

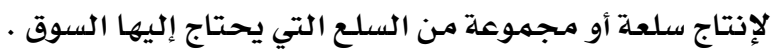

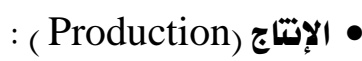

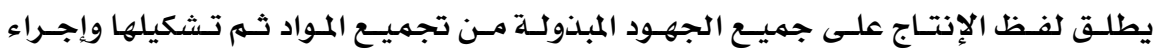

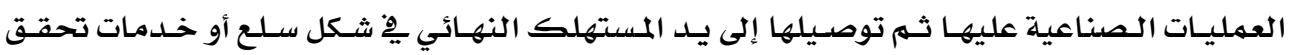

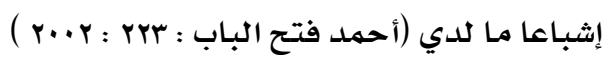

\section{• مفهوم الإتتاجية :}

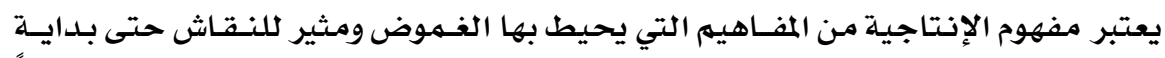

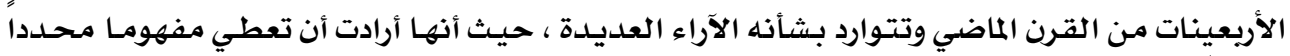

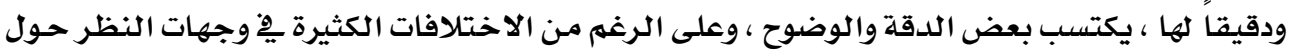

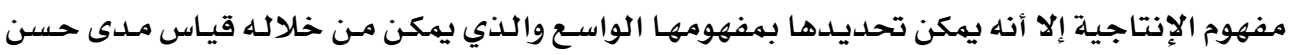

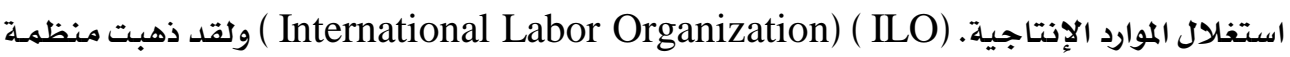

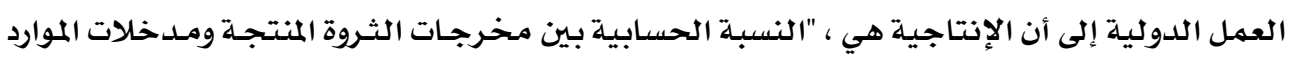

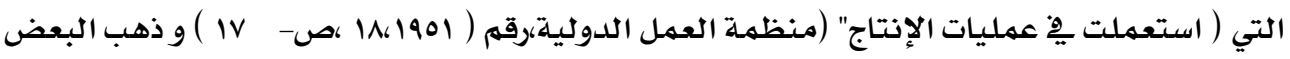

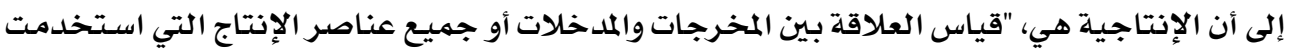

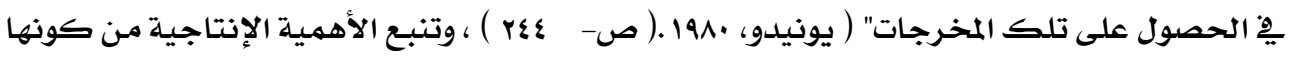

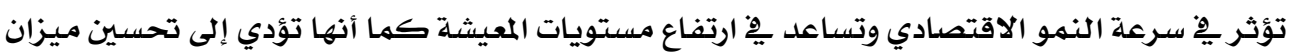

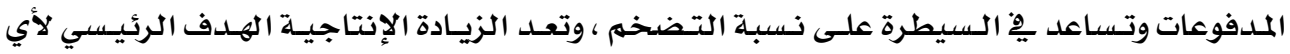

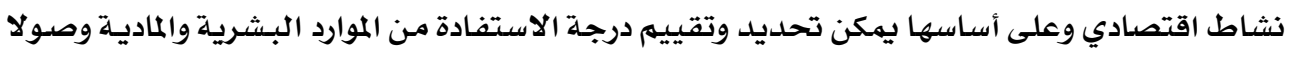

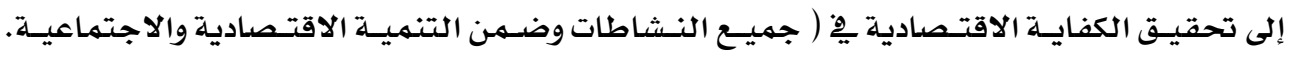

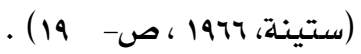

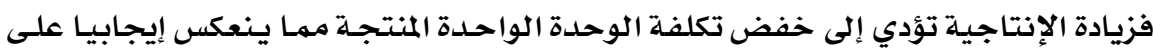

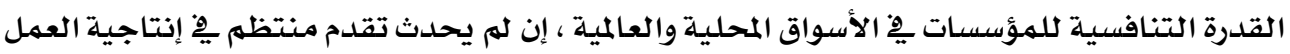

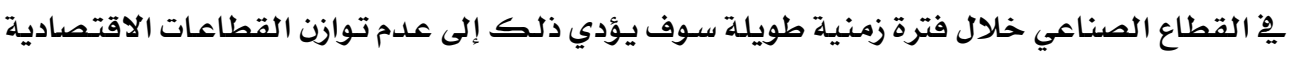

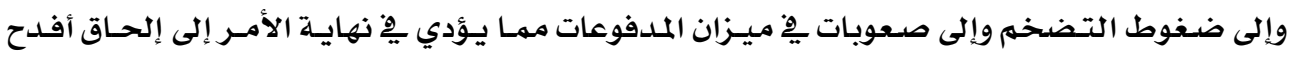

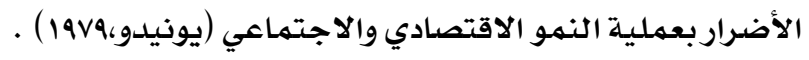

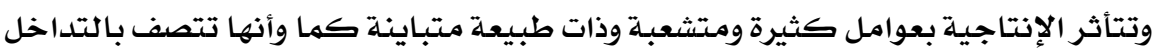

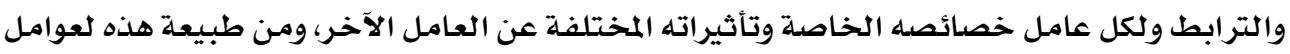

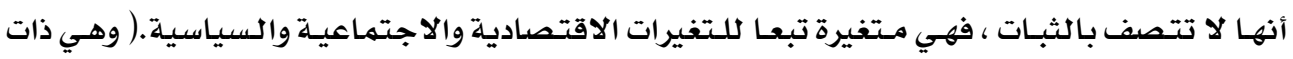

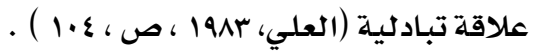


ومهـا لا شـك فيـه أن تحسـين الإنتاجيـة غير ممكـن إلا بتأديـة الأعمـال بطريقـة صسحيحلة ،

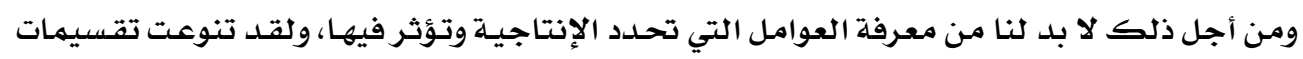

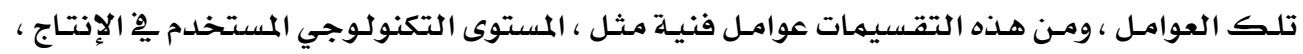

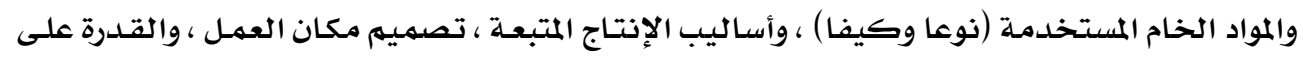

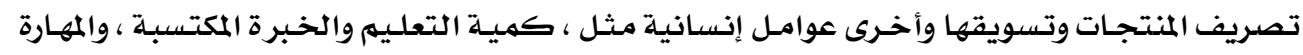

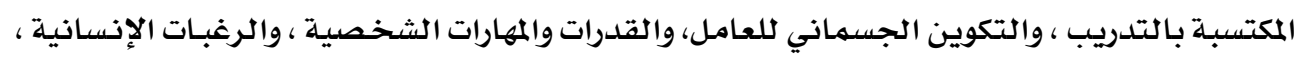

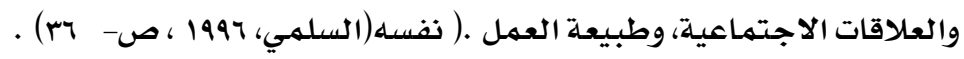

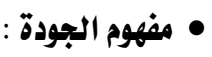

الجودة هي درجة وفاء المنتج لاحتياجات ورغبـات المستهلك ، يعتبر المنتج على درجـة عاليـة

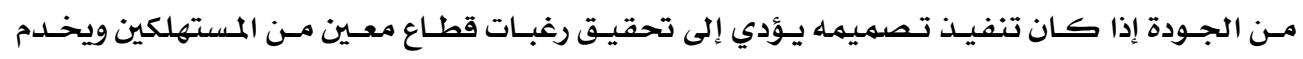

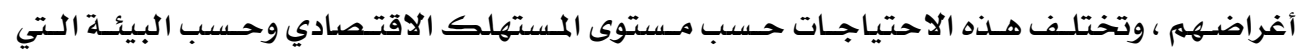
يعيشها.

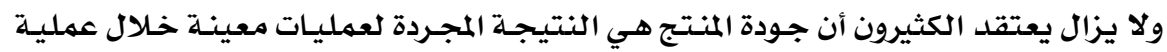

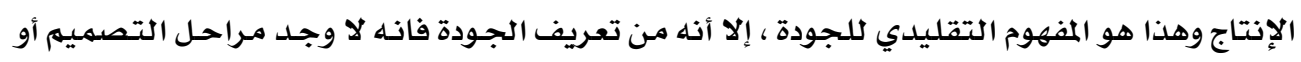

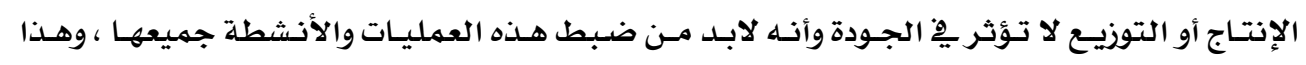

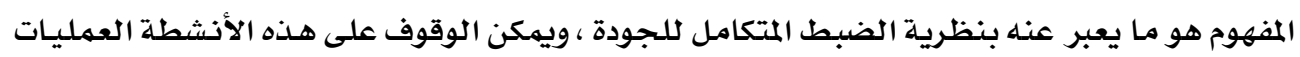

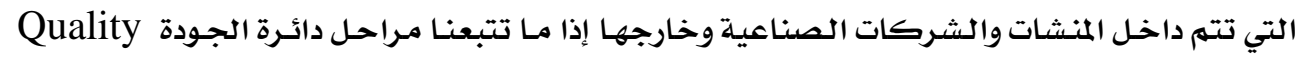

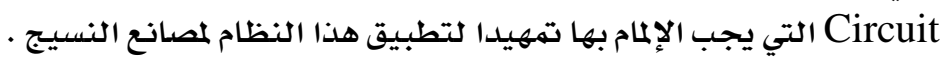

أهداف وضوابط الجودة :

هدف نظام ضبط الجودة إلى :

الاستخدام الأمثل للآلات والمعدات المتاحة.

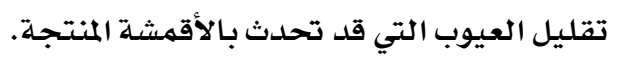

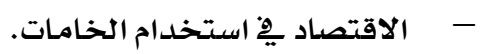

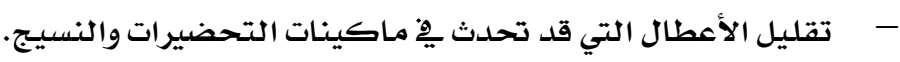

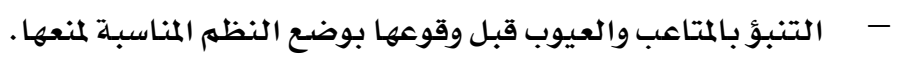

- تقليل شكاوي العملاء واكتساب الثقلة.

أهم المشاكل والمعوقات التي تواجه فرع صناعة النسيج :

- عدم وجود قوانين إدارية وتنظيمية للاتحادات تحدد طريقة.

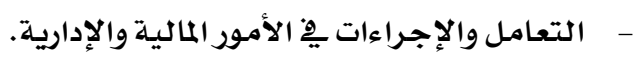

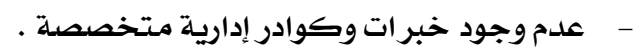

عدم وجود مصادر تمويل كافية خصوصدا لمرحلة البناء . 
عدم وجود قنوات اتصال مـع الاتحادات الخارجية المثابهة وِِّح حال وجودهـا عدم الاستمرار بهـا

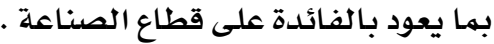

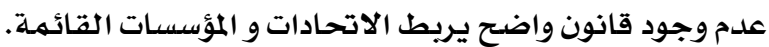

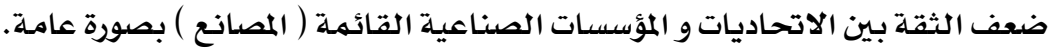

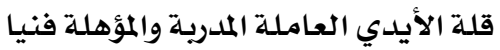

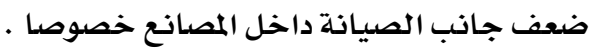
عدم وجود مناطق صناعية كافية . ضعف الروابط الشخصية بين أصحاب المصانع المتشابهة ( لوجـود منافسة دائمسة وليس تعـاون

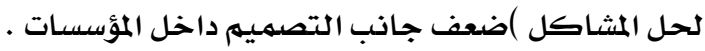

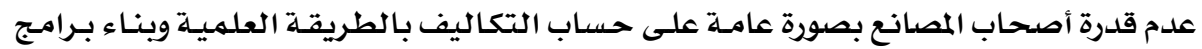
الإنتاج الكبيرة .

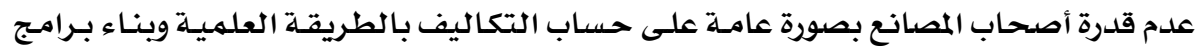
الإنتاج الكبيرة .

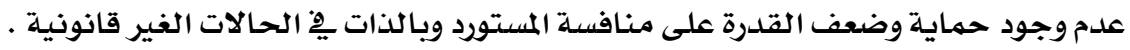

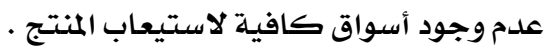

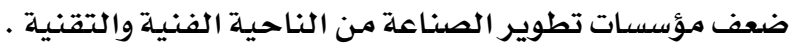

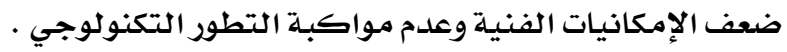

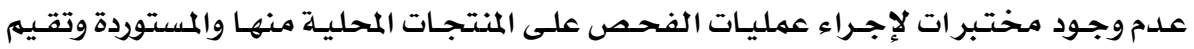

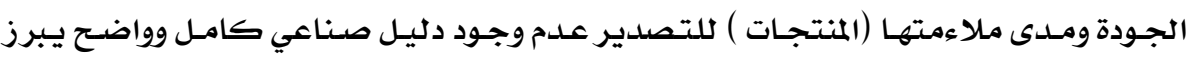

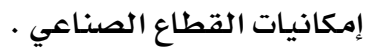
اعتماد عدد كبير من المؤسسات على التعاقد من الباطن حوالي ( •^٪) الإنتاج الكبيرة .

\section{الأسلوب المستخلم حاليا في عمليات الإنتاج وسلبياته :}

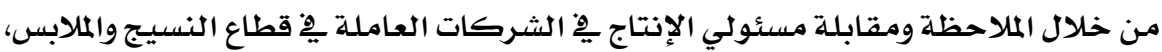

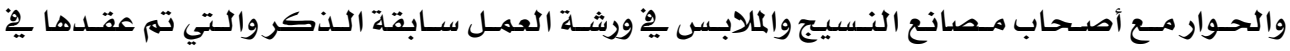

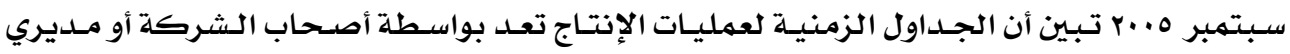

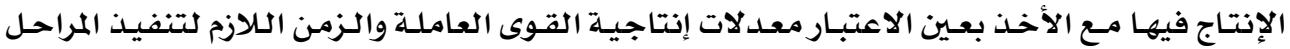

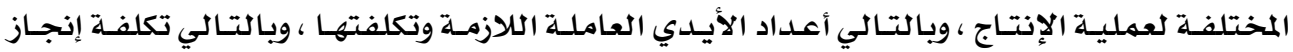

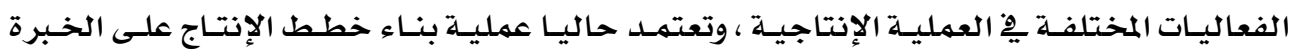

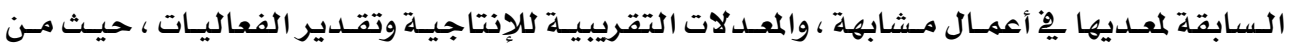

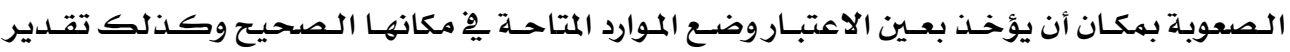

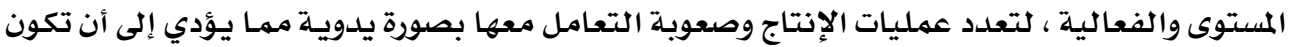

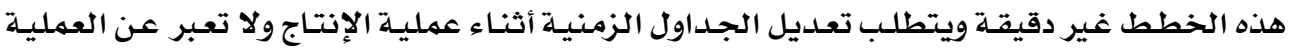

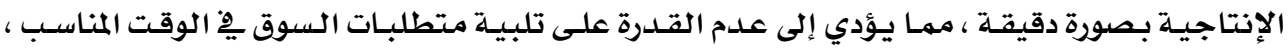


وأحياًنا تكون الشركات متعاقدة مـع جهات أخرى عن طريق المناقصات بعقود ملزمسة بمواعيد وتواريخ

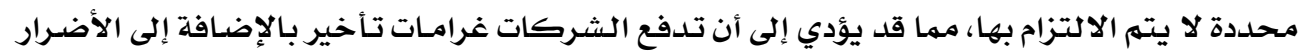

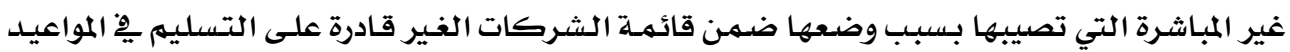

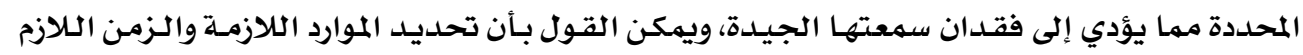

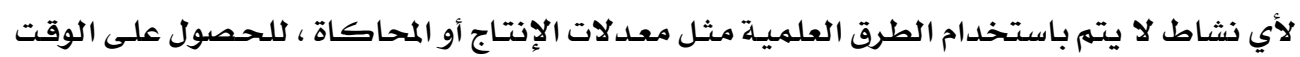

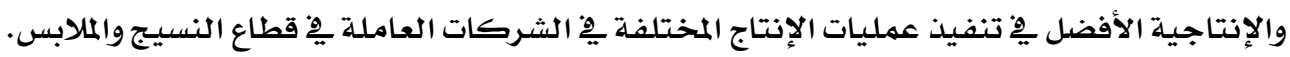

العواهل المؤثرة على الإنتاج

تتلخص العوامل المؤثرة على جودة المنتجة ِِّ مصانع النسيج ٍِِِ الأتي :

الإدارة المالية :

وهـي مـن الإدارات الرئيسيسية الـتي تتـولى إدارة أمـوال المشروع واسـتخدامها بالسشكل الأمثل

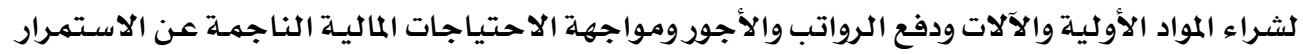

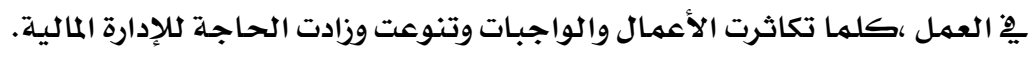

إدارة الإنتاج :

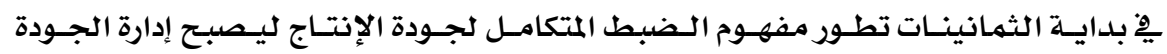

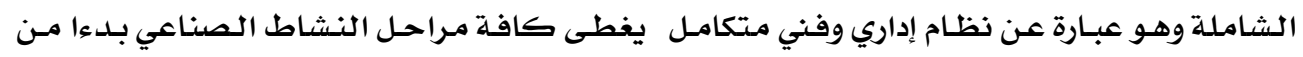

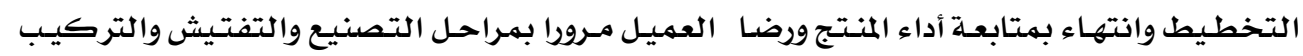

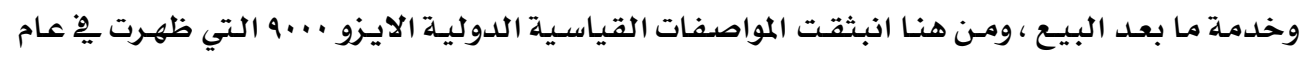

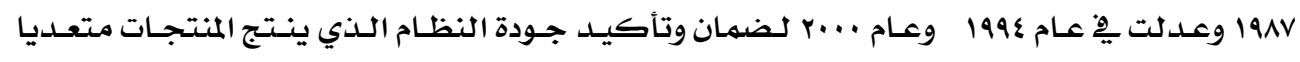

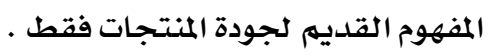

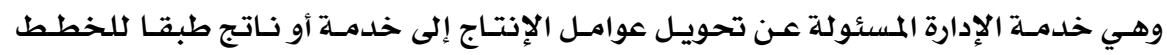

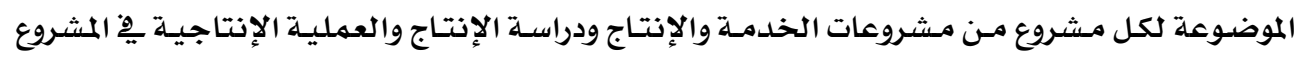

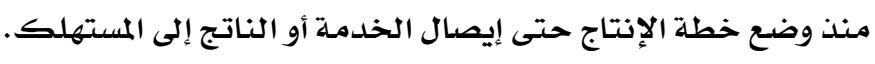

إدارة التسويث : مئر

ولها أهمية كبرى يِّن نشاط المشروع فهي تتولى إدارة المشروع بالتعـاون مـع الإدارة المخصصة

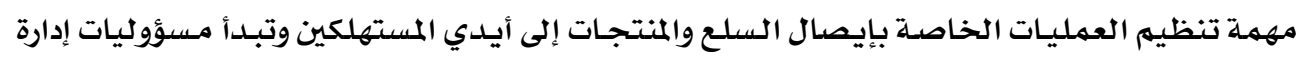
التسويق حيث ينتهي مسئوليات إدارة الإنتاج.

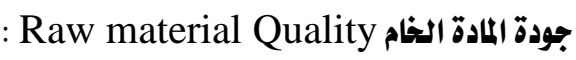

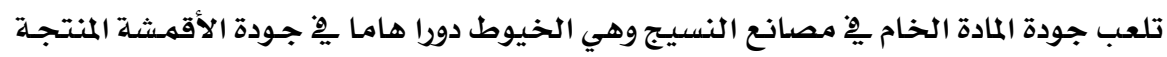

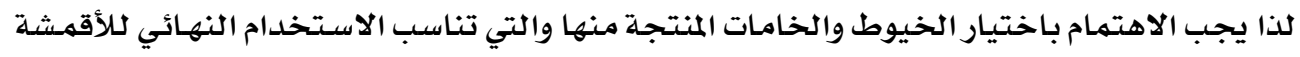

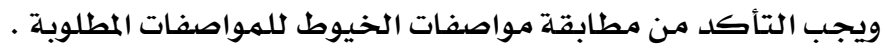


• إجراء الاختبارات المعملية على الخامات الواردة للمؤسسـة والتأكد مـن مطابقتها للمواصفات

$$
\text { المطلوبـة. }
$$

• التفتيث على المنتجـات بجميـع مراحل التشغيل والتأكـد مـن مطابقـة مواصفات المنتج بكل

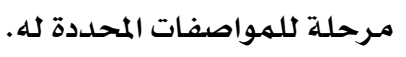

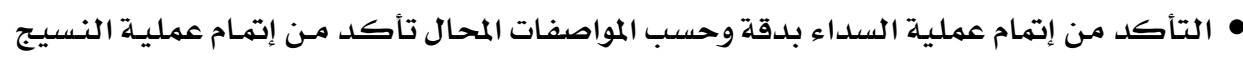

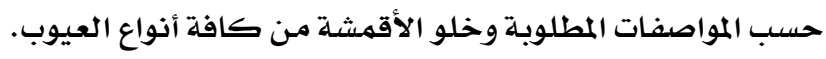

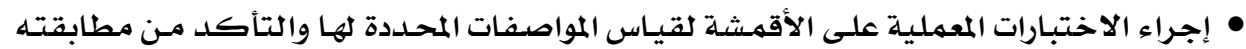

لها .

• إعداد التقارير والإحصاءات الخاصة بنتائج الفحص والاختبارات التي تمت.

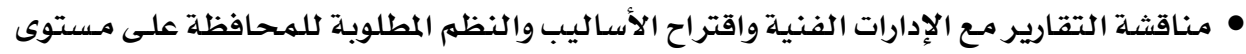

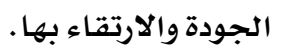

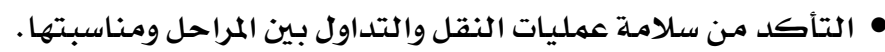

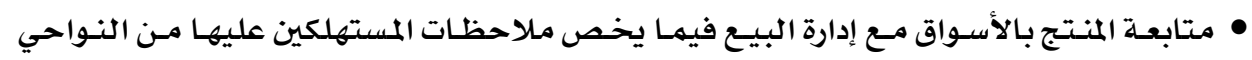

الفنية ومناسبتها للاستخدام.

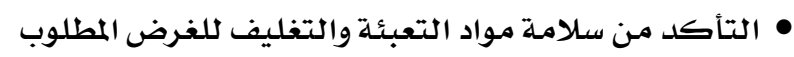

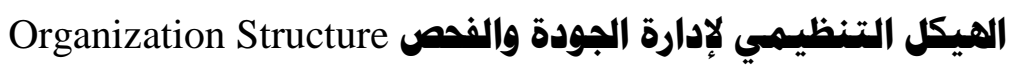

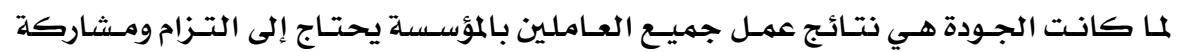

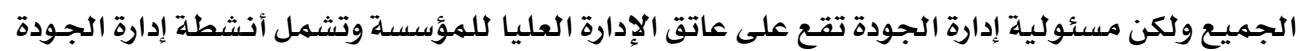

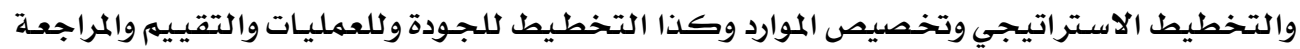

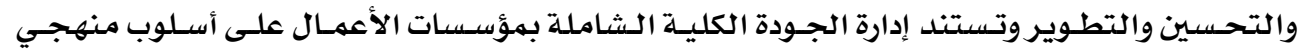

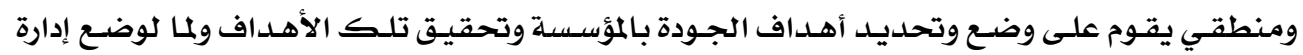

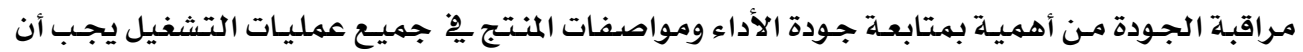

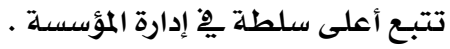

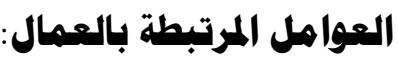

\section{ضبط الجودة عن طريق العامل :}

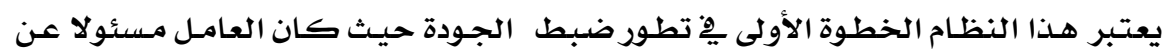

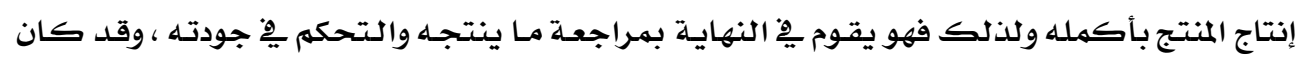

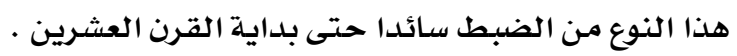




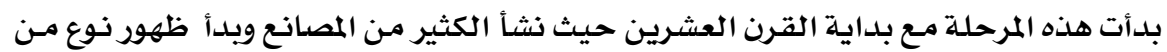

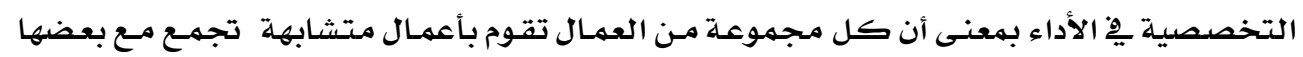

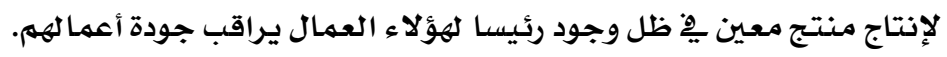

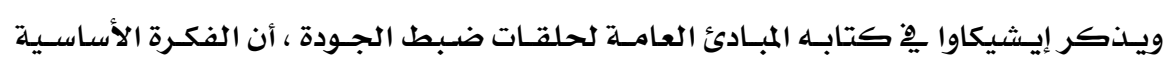
لحلقات ضبط الجودة تتمثل يٌْ :

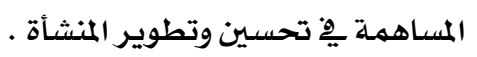

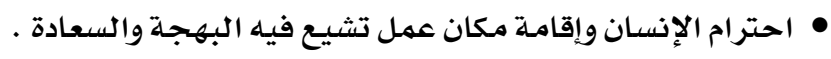

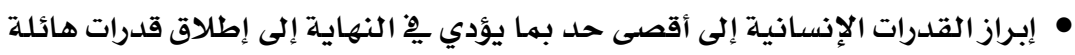

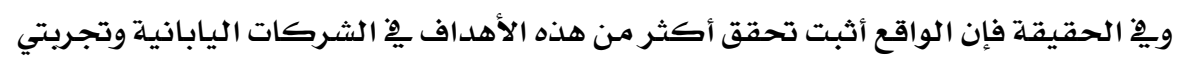

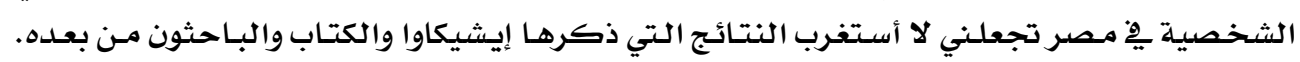

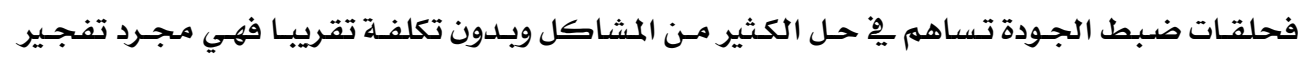

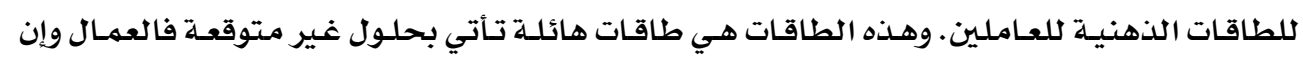

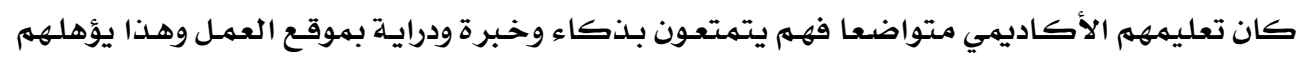
لكلإتيان بحلول للهشاكل وتحسين الكفاءة والجودة.

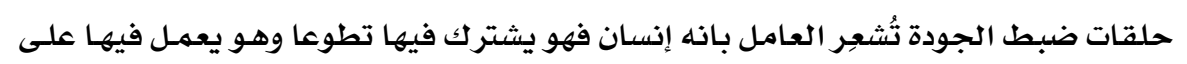

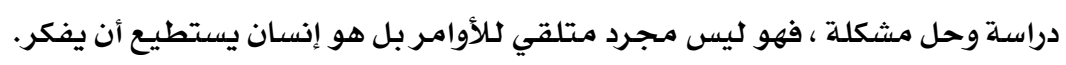

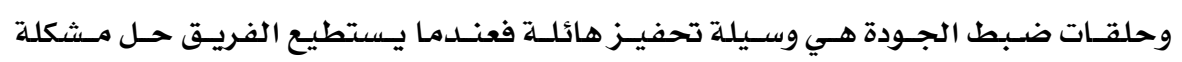

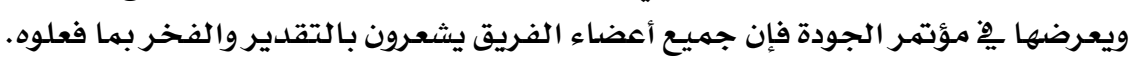

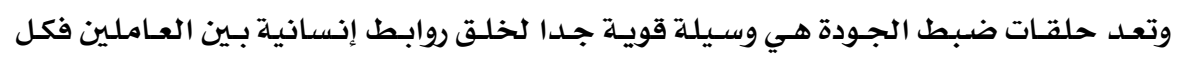

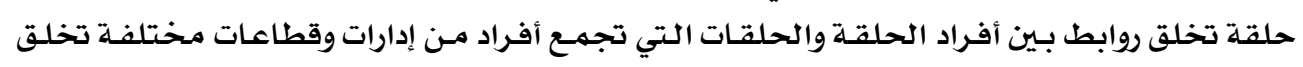

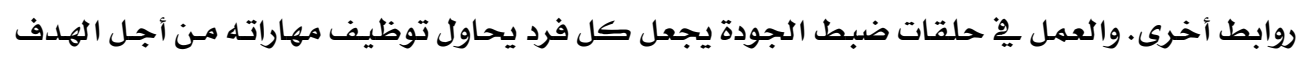

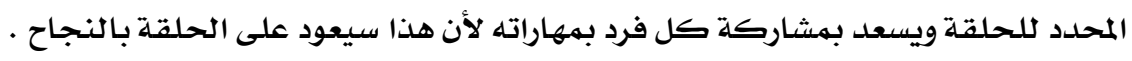

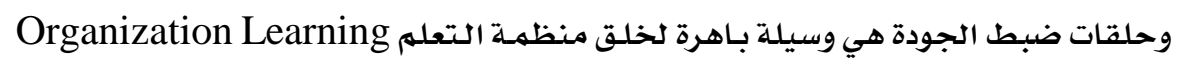

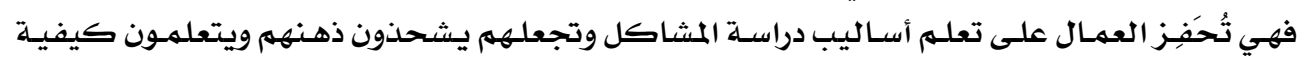

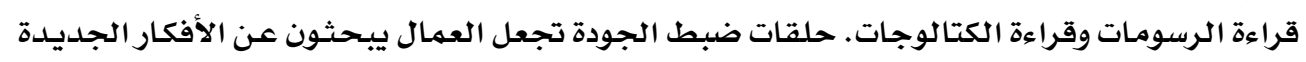

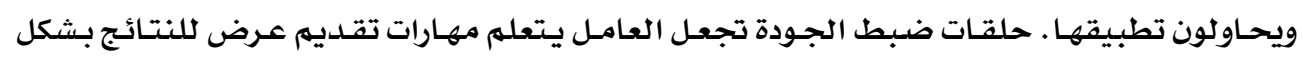

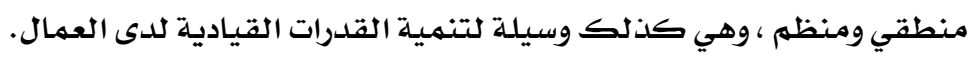

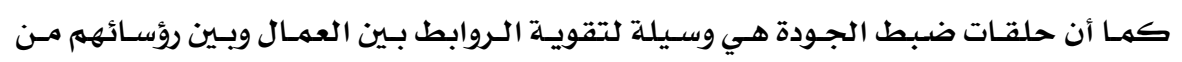

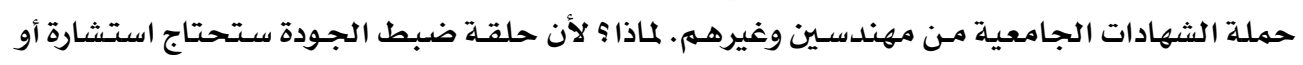

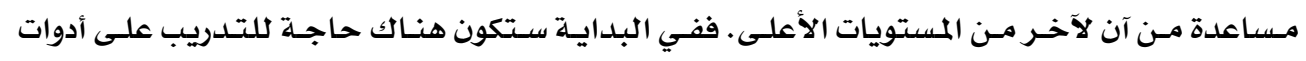




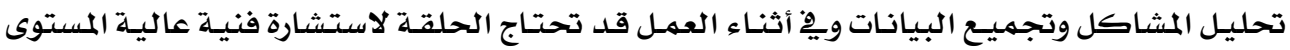

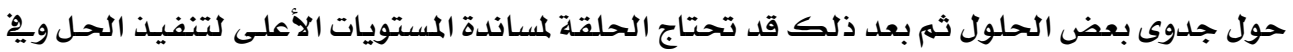

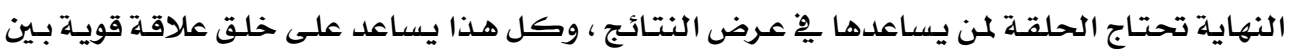

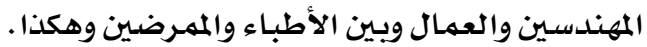

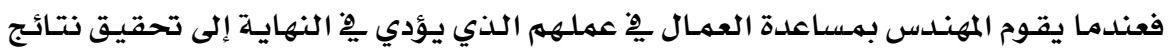

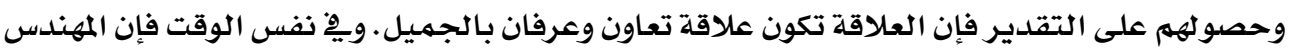

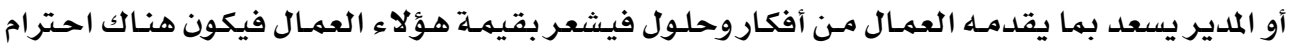
متبادل.

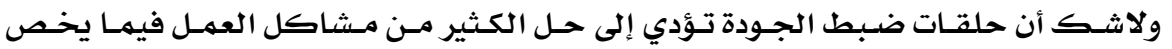

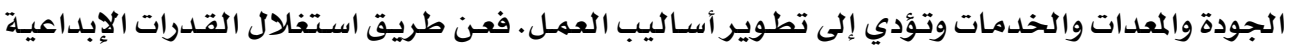

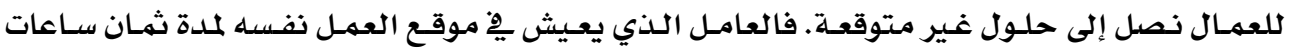

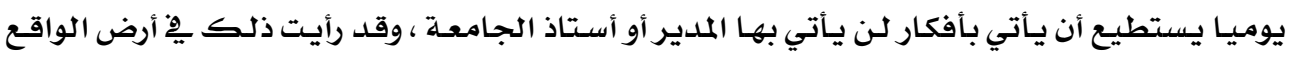

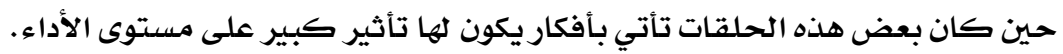

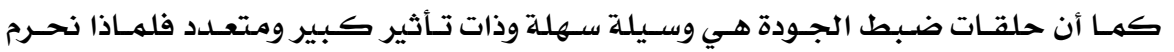

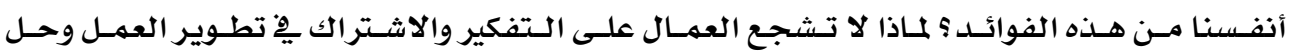

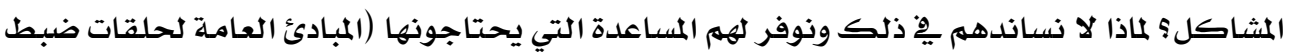
الجودة، كاورو إيشيكاوا، الطبعة العربية)

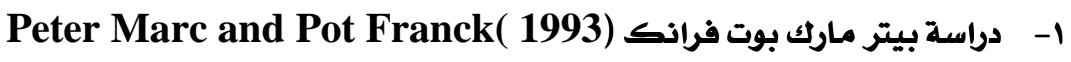

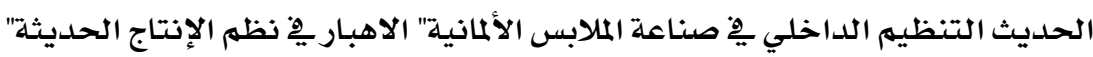

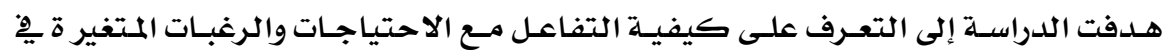

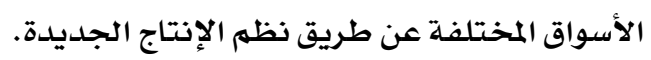

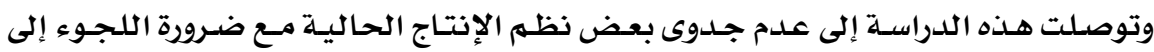

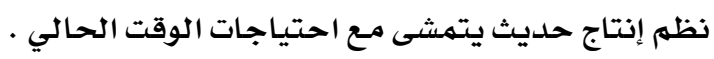

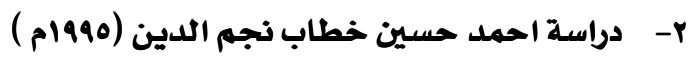
الصعوبات التي تواجه خطوط الإنتاج الملابس الجـاهزة ذات الإنتاج غير نهطي ووضـع بعض إسل

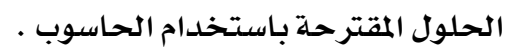

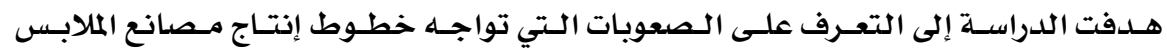

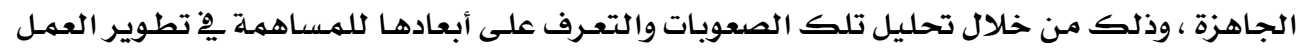




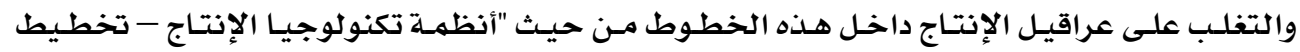

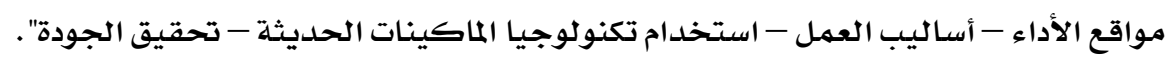

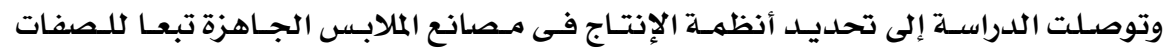

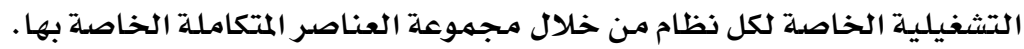

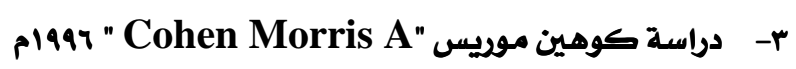
خطوط الإنتاج المتوازن "اتجاه حديث مِّو إدارة العمليات " .

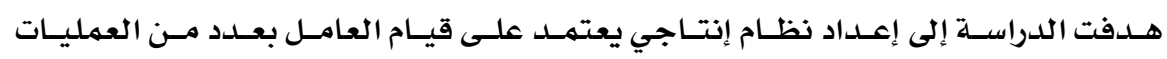

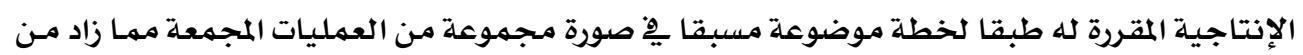
مهارة العامل وجودة المنتج

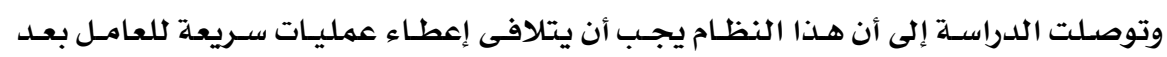

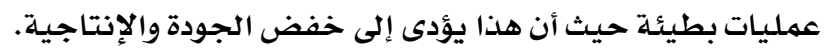
ع- دراسة احمد حسني خطاب 1991ام

طرق قياس وتحسين إنتاجية مصانع الملابس الجاهزة ِِّ مصر لتحقيق اتفاقية الجات .

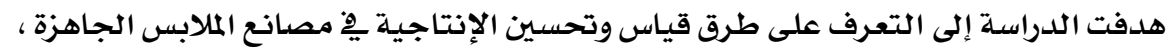

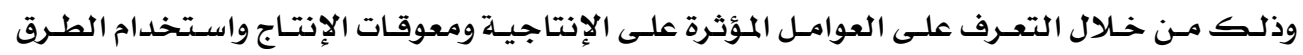

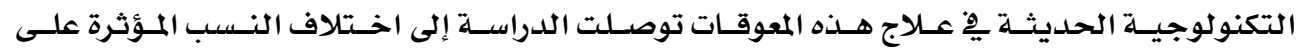
الإنتاجية.

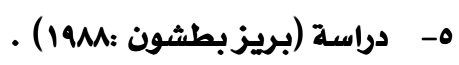

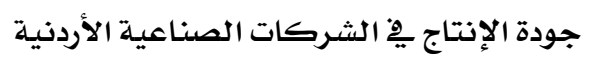

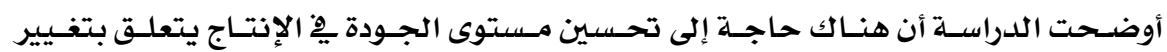

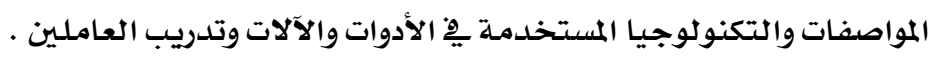
ج- دراسة (عبدا لله محمد 1999) . التتمية الصناعية يِ العالهم الثالث

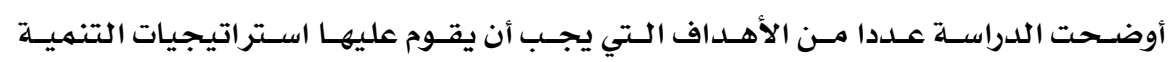

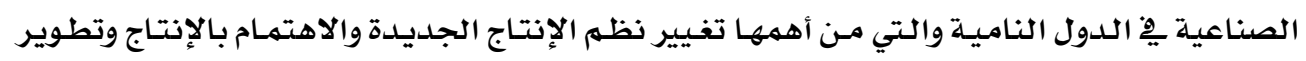

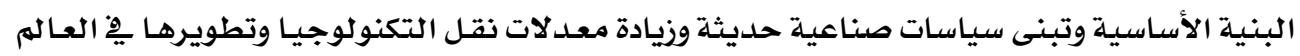
الثالث.

\section{التعليق على اللدراسات السابقة :}

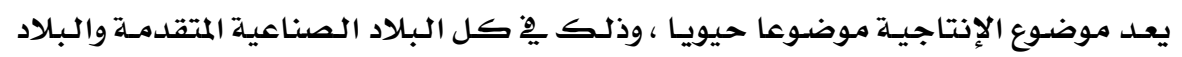

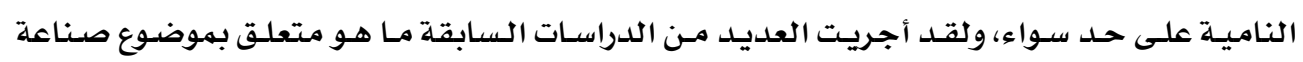


الملابس الجاهزة وعقدت الكثير مـن المؤتمرات والنـدوات على المستوى العـالمي والعربي أمـا فيمـا يتعلق

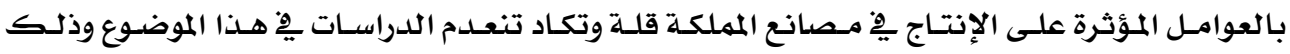

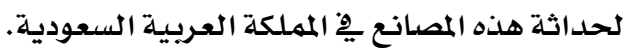

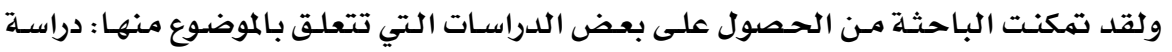

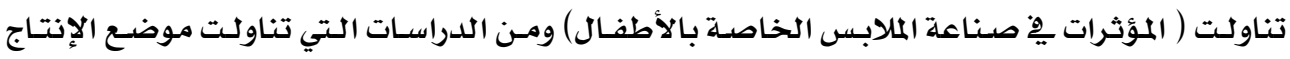

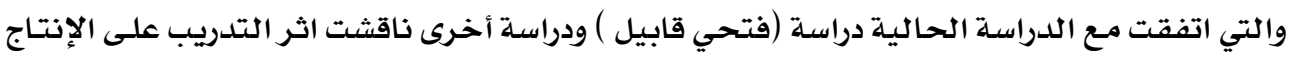

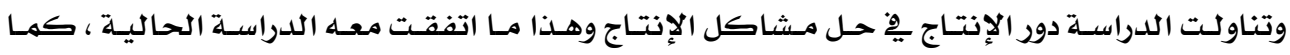

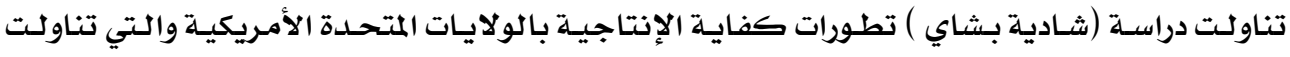

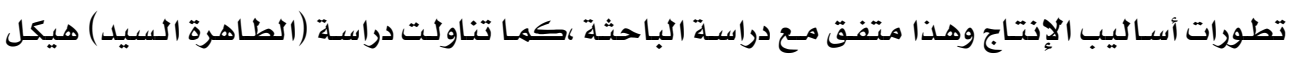

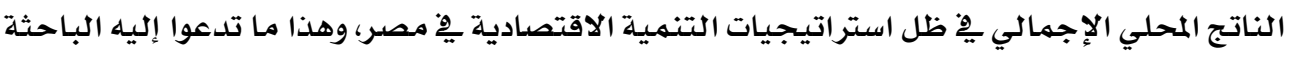

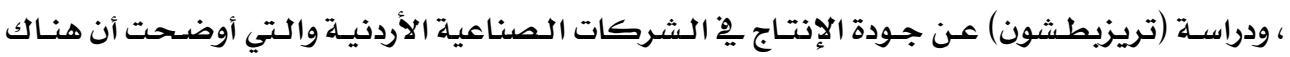

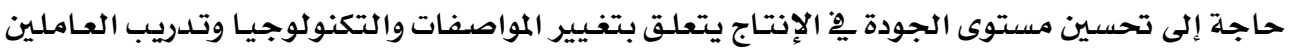

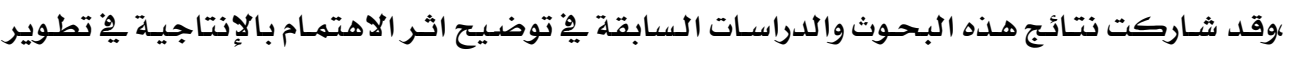

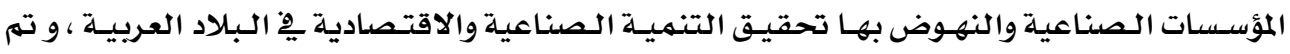

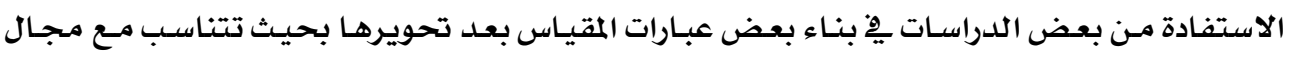
الدراسة .

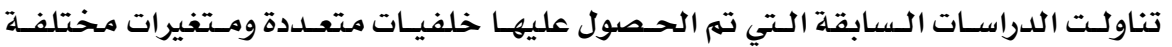

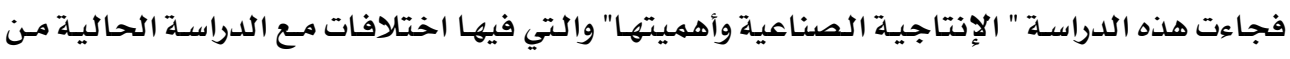

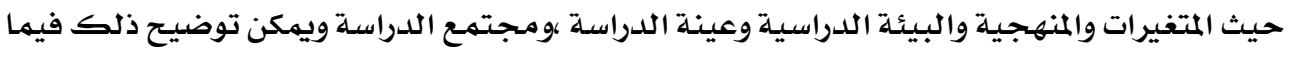
يلي :

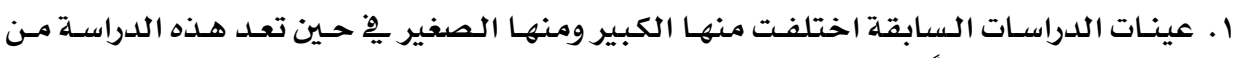

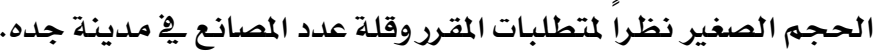

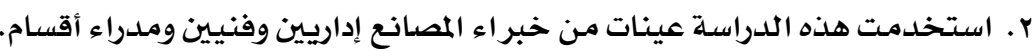

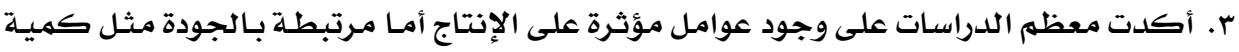

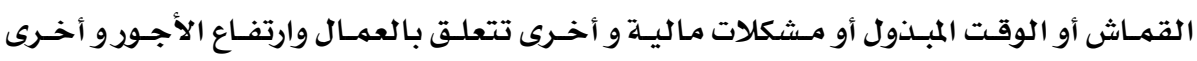

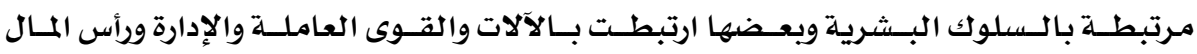
والتسويق • عربهن

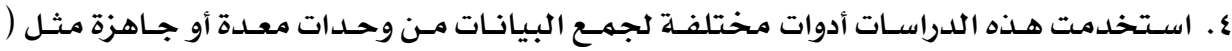

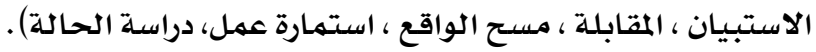

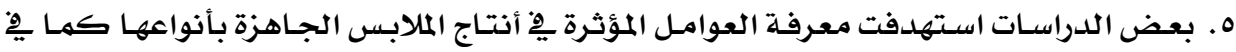

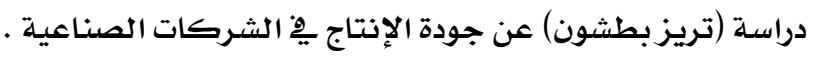




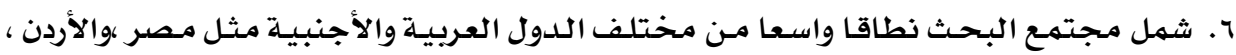

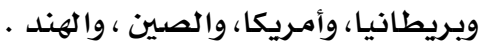

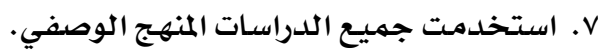

^. أظهرت نتائج الدراسـات السابقة عدد مـن العوامل المؤثرة المورة على أنتاج الملابس الجاهزة المتوافقة.

$$
\text { • هنالك اختلاف يِّ العوامل المؤثرة على إنتاج الملابس الجاهزة. }
$$

• استفادة الباحثة من تلك الدراسـات لأنها المصدر الأساسي للمعلومـات،والتي وجهت الباحثـة

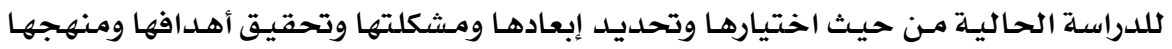

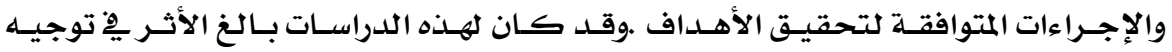

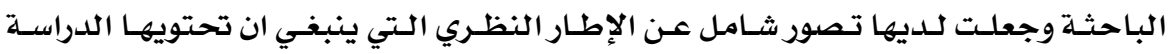

الحالية.

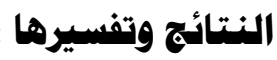

السؤال الأول: كيف يمكن بناء مقياس مقنن لقياس العوامل المؤثرة على الإنتاج ِِِ مصانع الملابس

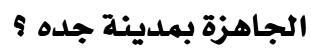

الخطوة الأولى :

نظـرا لاهتمـام الباحثـة بتخصـصها تـصنيع ملابس ونسيج ومهـا لاحظتـه أثنـاء الزيـارات

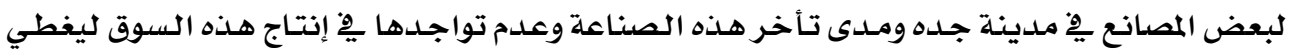

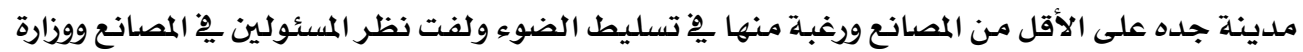

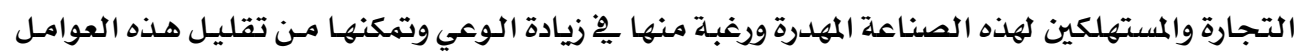

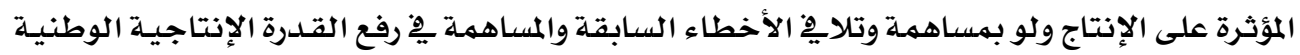

الخطوة الثانية :

إعداد الاستبيان ومصادر اشتقاق العبارات :

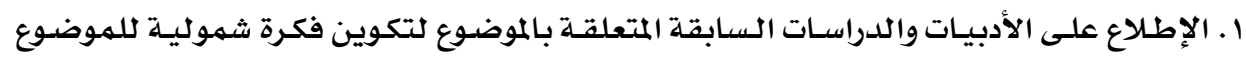

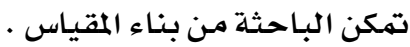

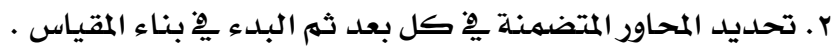

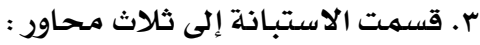

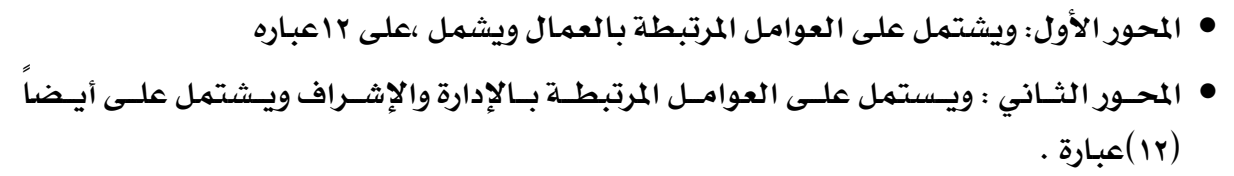

• المحور الثالث: ويشتهمل على العوامل المالية والمادية ويشتمل على( 19 ) ) عبارة .

ع. تحديد طريقة المفردات والبدائل من حيث الصياغة . 


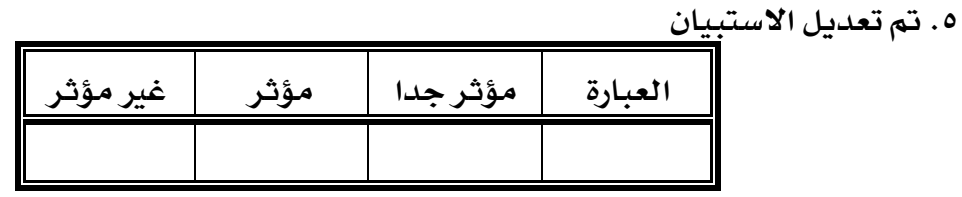

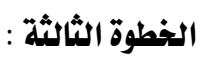

كيفيـة عرض الاستبيان على المحكمـين :

I. عرض المقياس على المجموعة من تخصصات مختلفة أثناء المحاضرة .

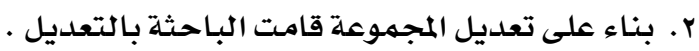

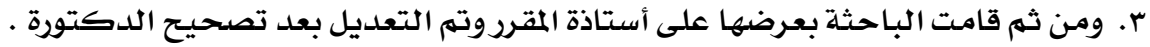

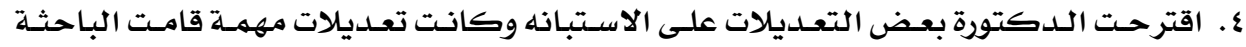

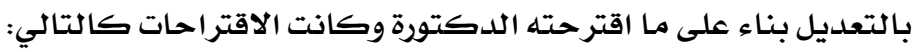

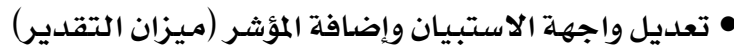

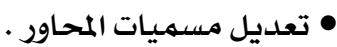

• تعديل بعض العبارات ونقل البعض الأخر إلى المحور الأخر الصحيح.

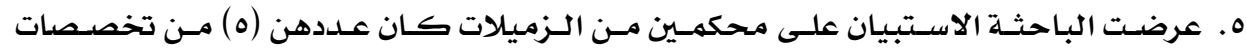

مختلفة.

الخطوة الرابعة :

عرضـت الباحثة الاستبيان على محكمهـين مـن التخصص ملابس ونسيج (تصنيع ملابس جاهزة) قبل الوصول إلى صورته النهائية.

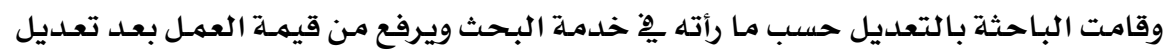

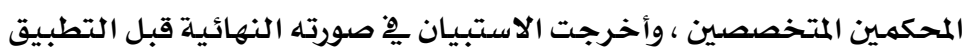

الخطوة الخامسة :

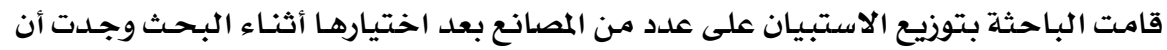

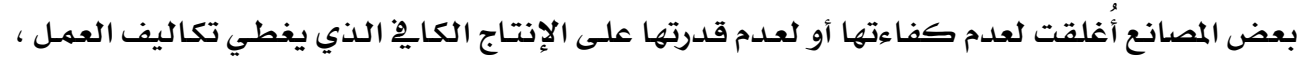

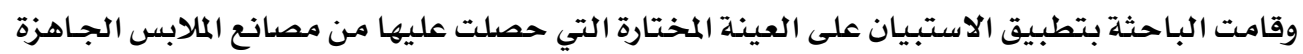

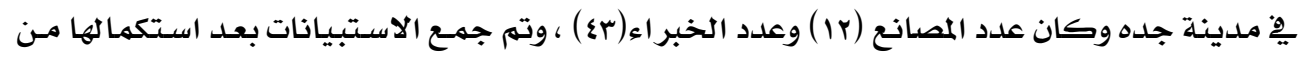

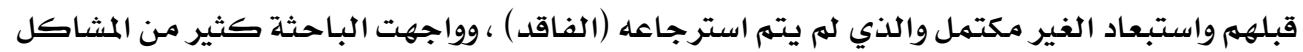

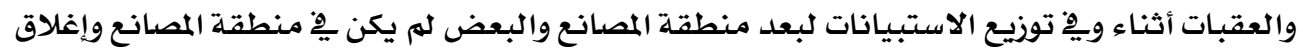

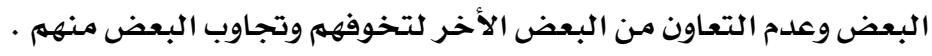


الإجابة على السؤال الثاني : ماهية الخصائص السيكومترية للاستبانة ؟

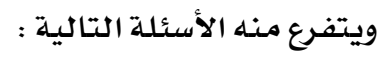

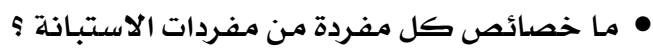

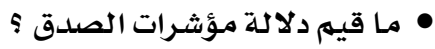

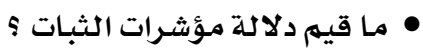

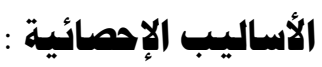

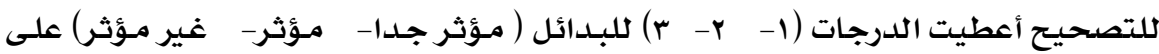

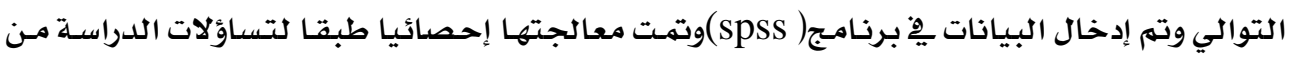

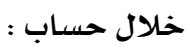

\section{أولاً: خصائص هناب: حفردات الاستبـانة :}

لحساب خصائص مفردات الاستبانة لكل مفردة فقد تم استخدام :

ا. التكرارات والنسب المئوية لكل مفردة على حله والجلدول التالي يوضح ذلك.

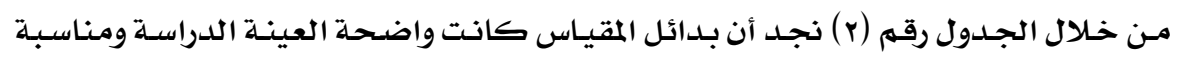

لعبارات المقياس

r. النسب المئوية لاتفاق المحكمين في المرحلة الثانية لقياس الصدق الظاهري لمفردات المقياس.

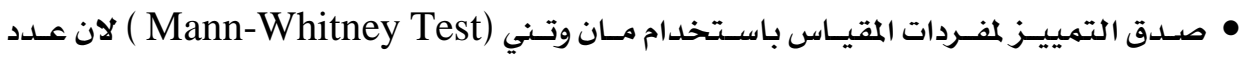

$$
\text { العينة قليل }
$$

• حساب معامل الاتساق الداخلي لمفردات المقياس (ثبات فقرات المقياس) باستخدام :

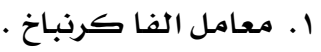

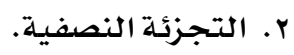




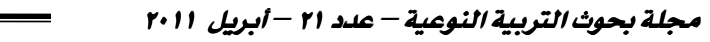

1 ـ التكرارات والنسب المئوية لكل هفردة على هدة ، والجدول التالي يوضج ذلك :

( التكراروالنسب المئوية لمفردات الاستبيان )

\begin{tabular}{|c|c|c|c|c|c|c|c|}
\hline \multicolumn{2}{|c|}{ غير هؤثر } & \multicolumn{2}{|c|}{ هؤثر } & \multicolumn{2}{|c|}{ هؤثر جدا } & العبارة & الرقم \\
\hline ذ & 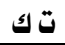 & ن & ت ك ك & 广 & ت ك & ور الأول: العوامل المرتبطة بالعمال & \\
\hline $\mid \xi, \gamma$ & 0 & $r r, \xi$ & 11 & $o r, q$ & in & علد العمال في المصنع & 1 \\
\hline iv, 7 & 7 & ro,r & ir & s, 1 & 19 & الأجر الشهري للعمال & r \\
\hline$r \cdot, r$ & $\checkmark$ & $\xi 1, r$ & ir & $r \Lambda, r$ & ir & 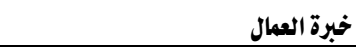 & $r$ \\
\hline$r \cdot, r$ & v & $\varepsilon \vee, 1$ & 17 & $r r, \xi$ & 11 & وقت العمل الإضافي & $\varepsilon$ \\
\hline$r \cdot, 7$ & v & $r r, \xi$ & 11 & $\{v, 1$ & 17 & تفيير العمال داخل خط الإتتاج & 0 \\
\hline$r q, \xi$ & 1. & «, 1 & 17 & $r r, 0$ & $\wedge$ & عدد العمال الذين تنتهي خدمتهم سنويا & 7 \\
\hline$r r, 0$ & $\wedge$ & ro,r & ir & $\xi 1, r$ & $1 \varepsilon$ & نسبة غياب العمال & $\checkmark$ \\
\hline$\Lambda, \wedge$ & $r$ & or, 9 & 14 & $r \Lambda, r$ & ir & نوعية مستوى المهارة & $\wedge$ \\
\hline 0,9 & r & $\xi 1, r$ & 10 & 0,0 & iv & مستوى المنتج النهائي & 9 \\
\hline $\mid \xi, \vee$ & 0 & $\xi 1, r$ & $1 \varepsilon$ & $\xi \xi, 1$ & is & نوع الآلات المستخدمة من حيث جودتها & 1. \\
\hline$r q, 0$ & 9 & $\xi 1, r$ & \& & $r r, \xi$ & 11 & الوعي الصناعي & 11 \\
\hline r., & $v$ & rA, rr & ir & $\xi 1, r$ & is & الخبرات العملية في خطوات التشفيل & ir \\
\hline
\end{tabular}

\begin{tabular}{|c|c|c|c|c|c|c|c|}
\hline \multicolumn{2}{|c|}{ غير هؤثر } & \multicolumn{2}{|c|}{ هوئثر } & \multicolumn{2}{|c|}{ هؤثر جدا } & العبارة & الرقم - الريم \\
\hline ن & ت ك & ن. & 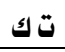 & $\%$ & 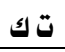 & \multicolumn{2}{|c|}{ المحور الثاني : عوامل المرتبطة بالإدارة والإشراف } \\
\hline $\mid \xi, Y$ & 0 & $r \Lambda, r$ & ir & $\varepsilon v, 1$ & 17 & إتباع أساليب الإحلال والتجديد & 1 \\
\hline$r q, \xi$ & 1. & $\mathrm{rq}, 0$ & 9 & $\llbracket \xi, 1$ & 10 & الأسلوب المتبع في الإشراف & r \\
\hline iv, 7 & 1 & $0 \cdot, \cdot$ & iv & rr, \& & 11 & إتباع أساليب الصيانة الوقائية & $r$ \\
\hline Try. & 7 & ro,r & ir & $\varepsilon v, 1$ & 17 & نظام إتتاج (بالقطعة أو بالطلب) & $\varepsilon$ \\
\hline rr,o & $\wedge$ & $\llbracket \S, 1$ & 10 & rr, & 11 & رصد معدلات أداء الأعمال والأنشطة & 0 \\
\hline iv, 7 & 7 & $r \Lambda, r$ & ir & $\llbracket \xi, 1$ & 10 & منافذ وقنوات التوزيع & 7 \\
\hline$i v, 7$ & 1 & $\xi \vee, 1$ & 17 & $r 0, r$ & ir & التدريب والإرشاد & v \\
\hline iv, 7 & 1 & $\xi \vee, 1$ & 17 & $r 0, r$ & ir & نوع الخامة المستخدمة & $\wedge$ \\
\hline iv, 7 & 7 & $r v, 1$ & 17 & $r 0, r$ & ir & التخطيط المسبق قبل الإتتاج & 9 \\
\hline $\mathrm{m}, 0$ & 9 & $r \Lambda, r$ & ir & $r 0, r$ & ir & الاستعانة بالأبحاث العلمية والأكاديمية & 1. \\
\hline ro,r & ir & $r r, \xi$ & 11 & rr, \& & 11 & قواذين حماية المنتجات الوطنية & 11 \\
\hline$r q, \varepsilon$ & 1. & $r r, 0$ & $\wedge$ & $\varepsilon v, 1$ & 17 & الخبرات للدى مراقبي الإتتاج & ir \\
\hline
\end{tabular}


العوامل المؤثرة على الإنتاج ِِ صناعة الملابس الجاهزة بملينة جلة

\begin{tabular}{|c|c|c|c|c|c|c|c|}
\hline \multicolumn{2}{|c|}{ فير هؤثر } & \multicolumn{2}{|c|}{ هؤثر } & \multicolumn{2}{|c|}{ هئثر جدا } & العبارة & الرقم \\
\hline ن & ت ك ك & ذ & ت ت ك & ذ & ت ك & لمحور الثالث: العوامل المالية والمادية & \\
\hline $11, \wedge$ & $\varepsilon$ & $r r, 0$ & $\wedge$ & $7 \xi, \vee$ & rr & هيكل التمويل & 1 \\
\hline IV, 7 & 7 & ro,r & ir & $\leqslant v, 1$ & 17 & نققات التشفيل & r \\
\hline $1 \xi, Y$ & 0 & ro, r & ir & $0 ., \cdot$ & iv & الرقابة المالية & $r$ \\
\hline$r r, O$ & $\wedge$ & $\xi v, 1$ & 17 & $r 9,8$ & 1. & نسبة المبيعات & $\varepsilon$ \\
\hline r., T & $r$ & $r \Lambda, r$ & ir & $\xi 1, r$ & $1 \xi$ & ارتفاع تكاليف الشحن والنقل & 0 \\
\hline IV, 7 & 7 & rq, ६ & 1. & or, 9 & in & زيادة تكلفة المواد الخام & 7 \\
\hline IV, 7 & 1 & $\varepsilon v, 1$ & 17 & ro,r & ir & ارتقاع نسبة التلف في المنتجات & $\checkmark$ \\
\hline$\wedge, \wedge$ & $r$ & or, 9 & 11 & $r \Lambda, r$ & ir & ارتقاع أجور العاملين & $\wedge$ \\
\hline $1 \xi, Y$ & 0 & 00,9 & 19 & $r q, \xi$ & 1. & زيادة المخزون من الخامات & 9 \\
\hline$r \cdot, r$ & $\checkmark$ & $\{\xi, 1$ & 10 & ro,r & ir & زيادة في أسعار استيراد المواد الخام & 1. \\
\hline$r r, 0$ & $\wedge$ & rr, & 11 & $\llbracket \varepsilon, 1$ & 10 & ضعف الإدارة المالية & 11 \\
\hline$r \cdot, r$ & $\checkmark$ & $r o, r$ & ir & $\llbracket \xi, 1$ & 10 & ضعف إدارة التسويق & ir \\
\hline IV, 7 & 7 & ro,r & ir & ro,r & 17 & ضعف إدارة التمويل & ir \\
\hline $1 \xi, Y$ & 0 & $0 \cdot, \cdot$ & iv & ro,r & ir & غياب الرقابة المالية & $1 \varepsilon$ \\
\hline$r r, 0$ & $\wedge$ & $0 \cdot, \cdot$ & iv & $r r, O$ & $\wedge$ & العلاقات مع البنوك المختلفة & 10 \\
\hline rq,o & 9 & $0 \cdot, \cdot$ & iv & $r q, 0$ & 9 & تنسيق العلاقة مع الأسواق المالية & 17 \\
\hline rr,o & $\Lambda$ & $0 \cdot, \cdot$ & iv & rq,o & 9 & تفيير خط الإتتاج & iv \\
\hline $1 \xi, v$ & 0 & $\xi \xi, 1$ & 10 & $\xi 1, r$ & $1 \xi$ & أعطال الماكينات & in \\
\hline ro,r & ir & $\xi \xi, 1$ & 10 & $r \cdot, 7$ & $\checkmark$ & المساحة المخصصة للتشفيل & 19 \\
\hline
\end{tabular}

التكررات والنسب المئوية للجزيء الثاني من الاستبـانه

\begin{tabular}{|c|c|c|c|c|c|}
\hline \multicolumn{2}{|c|}{ سلبي } & \multicolumn{2}{|c|}{ ايجابي } & العبارة & الرقم \\
\hline$\%$ & 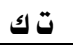 & $\%$ & 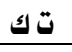 & المحور الأول: العوامل المرتبطة بالعمال & \\
\hline 20.6 & 7 & 79.4 & 27 & عدد العمال في المصنع & 1 \\
\hline 35.3 & 12 & 64.7 & 22 & الأجر الشهري للعمال & r \\
\hline 17.6 & 6 & 82.4 & 28 & خبرة العمال & $r$ \\
\hline 41.2 & 14 & 58.8 & 20 & وقت العمل الإضافي & $\varepsilon$ \\
\hline 38.2 & 13 & 61.8 & 21 & تفيير العمال داخل خط الإتتاج & 0 \\
\hline 29.4 & 10 & 70.6 & 24 & عدد العمال الذيز تنتهي خدمتهم سنويا & 7 \\
\hline 32.4 & 11 & 67.6 & 23 & نسبة غياب العمال & $\checkmark$ \\
\hline 29.4 & 10 & 70.6 & 24 & نوعية مستوى المهارة & $\wedge$ \\
\hline 29.4 & 10 & 70.6 & 24 & مستوى المنتج النهائي & 9 \\
\hline 23.5 & 8 & 76.5 & 26 & نوع الآلات المستخدمة من حيث جودتها & 1. \\
\hline 35.3 & 12 & 64.7 & 22 & الوعي الصناعي & 11 \\
\hline 32.4 & 11 & 67.6 & 23 & الخبرات العملية في خطوات التشفيل & ir \\
\hline
\end{tabular}




\begin{tabular}{|c|c|c|c|c|c|}
\hline \multicolumn{2}{|c|}{ ايجابي } & \multicolumn{2}{|c|}{ 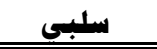 } & العبارة & الرقم - الرم \\
\hline ذ & ت ك & ذ & ت ك & الثاني : عوامل المرتبطة بالإدارة والإشراف & \\
\hline 35.3 & 12 & 67.6 & 23 & إتباع أساليب الإحلال والتجديد & 1 \\
\hline 32.4 & 11 & 67.6 & 23 & الأسلوب المتبع في الإشراف & $r$ \\
\hline 35.3 & 12 & 64.7 & 22 & إتباع أساليب الصيانة الوقائية & $r$ \\
\hline 32.4 & 11 & 67.6 & 23 & نظام إتتاج (بالقطعة أو بالطلب) & $\varepsilon$ \\
\hline 29.4 & 10 & 70.6 & 24 & رصد معدلات أداء الأعمال والأنشطة & 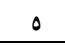 \\
\hline 47.1 & 16 & 52.9 & 18 & منافذ وقنوات التوزيع & 1 \\
\hline 38.2 & 13 & 61.8 & 21 & التدريب والإرشاد & $r$ \\
\hline 29.4 & 10 & 70.6 & 24 & نوع الخامة المستخدمة & $\wedge$ \\
\hline 29.4 & 10 & 70.6 & 24 & التخطيط المسبق قبل الإتتاج & 9 \\
\hline 23.5 & 8 & 76.5 & 26 & الاستعانة بالأبحاث العلمية والأكاديمية & 1. \\
\hline 23.5 & 8 & 76.5 & 26 & قوانين حماية المتتجات الوطنية & 11 \\
\hline 26.5 & 9 & 73.5 & 25 & الخبرات لدى مراقبي الإتتاج & ir \\
\hline
\end{tabular}

\begin{tabular}{|c|c|c|c|c|c|}
\hline \multicolumn{2}{|c|}{ ايجابي - ابي } & \multicolumn{2}{|c|}{ سلبي } & العبارة & الرقم \\
\hline ذ & ت ك ك & ذ & ت ك & المحور الثالث: العوامل المالية والمادية & \\
\hline 26.5 & 9 & 73.5 & 25 & هيكل التمويل & 1 \\
\hline 32.4 & 11 & 67.6 & 23 & نققات التشفيل & r \\
\hline 29.4 & 10 & 70.6 & 24 & الرقابة المالية & $r$ \\
\hline 32.4 & 11 & 67.6 & 23 & نسبة المبيعات & $\varepsilon$ \\
\hline 35.3 & 12 & 64.7 & 22 & | ارتفاع تكاليف الشحن والنقل & 。 \\
\hline 41.2 & 14 & 58.8 & 20 & | زيادة تكلفة المواد الخام & 1 \\
\hline 41.2 & 14 & 58.8 & 20 & | ارتفاع نسبة التلف في المنتجات & $r$ \\
\hline 41.2 & 14 & 58.8 & 20 & | ارتفاع أجور العاملين & $\wedge$ \\
\hline 38.2 & 13 & 61.8 & 21 & ز زيادة المخزون من الخامات & 9 \\
\hline 41.2 & 14 & 58.8 & 20 & ز زيادة في أسعار استيراد المواد الخام & 1. \\
\hline 41.2 & 14 & 58.8 & 20 & | ضعف الإدارة المالية & 11 \\
\hline 44.1 & 15 & 55.9 & 19 & ضعف إدارة التسويق & ir \\
\hline 47.1 & 16 & 52.9 & 18 & | ضعف إدارة التمويل & ir \\
\hline 41.2 & 14 & 58.8 & 20 & |غياب الرقابة المالية & $1 \xi$ \\
\hline 29.4 & 10 & 70.6 & 24 & العلاقات مع البنوك المختلفة & 10 \\
\hline 32.4 & 11 & 67.6 & 23 & تنسيق العلاقة مع الأسواق المالية & 17 \\
\hline 29.4 & 10 & 70.6 & 24 & تفيير خط الإتتاج & iv \\
\hline 29.4 & 10 & 70.6 & 24 & أعطال الماكينات & in \\
\hline 26.5 & 9 & 73.5 & 25 & المساحة المخصصة للتشفيل & 19 \\
\hline
\end{tabular}


مُعامـلات التمييز: تم حسابها عن طريق استخدام معامل الارتباط بيرسون، بحيث تم حساب

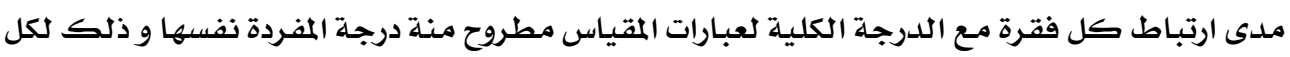

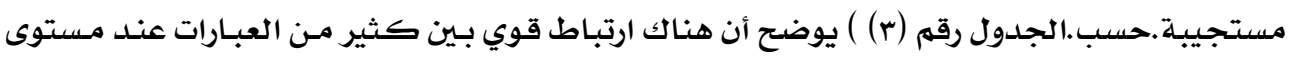

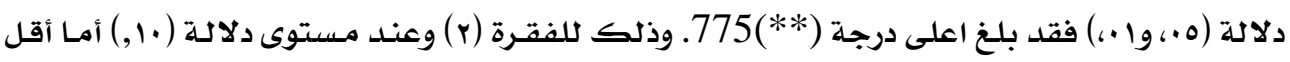

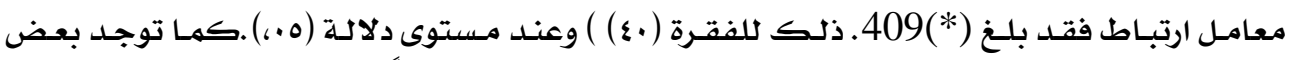

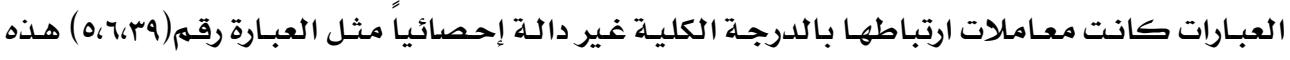

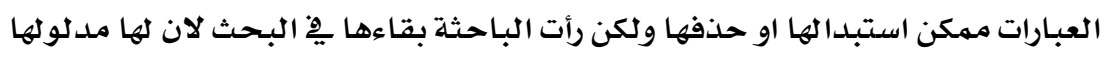

\begin{tabular}{|c|c|c|c|c|c|}
\hline معامل الارتباط & رقم الفقرة & معامل الارتباط & رقم الفقرة & معامل الارتباط & رقم الفقرة \\
\hline $.532(* *)$ & ro & $.520(* *)$ & 11 & .245 & 1 \\
\hline $.697(* *)$ & rq & $.719(* *)$ & 19 & $.741(* *)$ & r \\
\hline $.599(* *)$ & rv & $.640(* *)$ & r. & $.665(* *)$ & $r$ \\
\hline $.615(* *)$ & ra & $.554(* *)$ & ri & $.368(*)$ & $\xi$ \\
\hline .259 & rq & $.619(* *)$ & rr & .203 & 0 \\
\hline $.409(*)$ & \&. & $.569(* *)$ & rr & .167 & 7 \\
\hline $.535(* *)$ & $\$ 1$ & $.669(* *)$ & rq & $.395(*)$ & $\checkmark$ \\
\hline $.473(* *)$ & $\xi r$ & $.568(* *)$ & ro & $.588(* *)$ & $\wedge$ \\
\hline \multirow[t]{9}{*}{$.552(* *)$} & $\varepsilon r$ & $.704(* *)$ & rq & $.426(*)$ & 9 \\
\hline & & $.532(* *)$ & $r v$ & $.524(* *)$ & 1. \\
\hline & & $.634(* *)$ & rA & $.621(* *)$ & 11 \\
\hline & & $.671(* *)$ & ra & $.388(*)$ & ir \\
\hline & & $.684(* *)$ & $r \cdot$ & $.650(* *)$ & ir \\
\hline & & $.677(* *)$ & r & $.571(* *)$ & 18 \\
\hline & & $.466(* *)$ & rr & $.584(* *)$ & 10 \\
\hline & & $.566(* *)$ & $r$ & $.713(* *)$ & 17 \\
\hline & & $.589(* *)$ & $r \varepsilon$ & $.775(* *)$ & iv \\
\hline
\end{tabular}

\section{ثانياً قيم ودلالة همؤشرات صدق الاستبانة:}

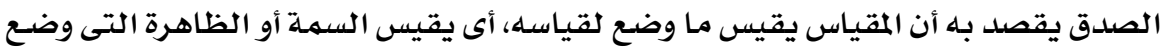

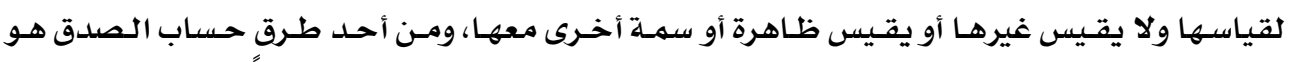

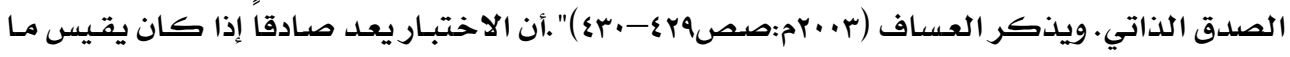

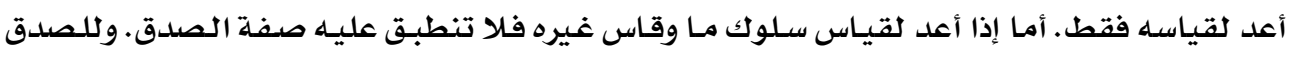

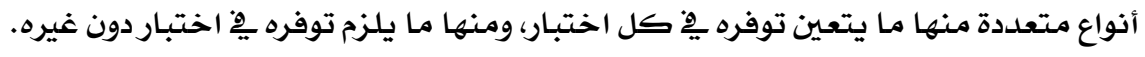
وقد اعتمدت الباحثة يِ حساب الصدق للاستبانة على الأتي : 
اـ صدق المحكمين :

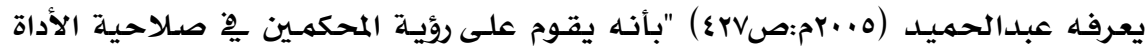

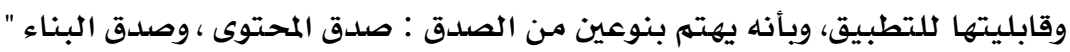

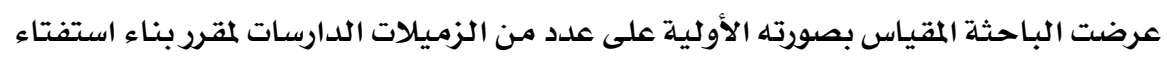

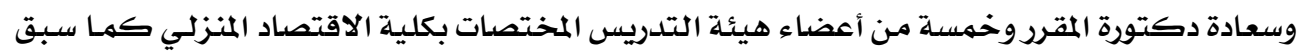

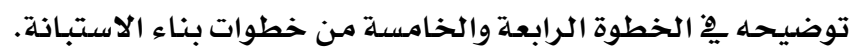

الاتساق الداخلي :

مصفوفة معاملات الارتباط :

تم حساب مصفوفة معاملات الارتباط (العبارة مـع الدرجـة الكلية مطروح منـه درجـة العبـارة

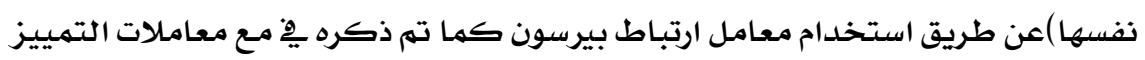

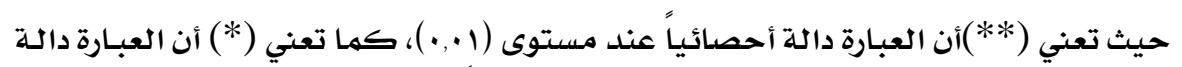

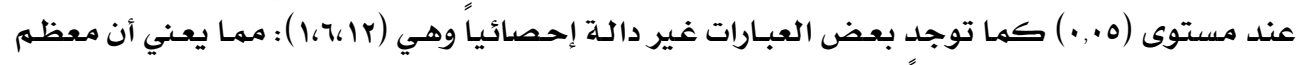

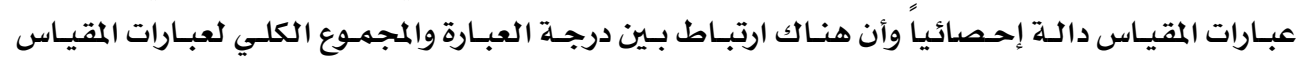

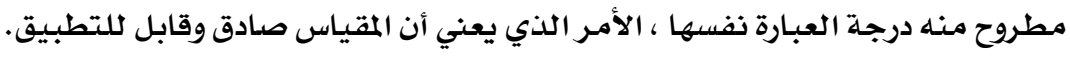

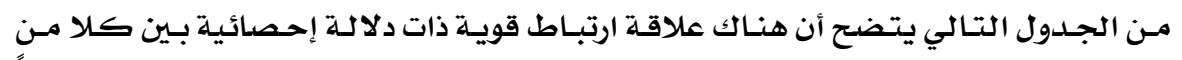

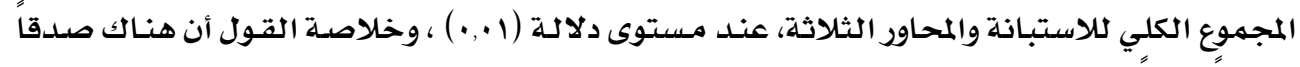

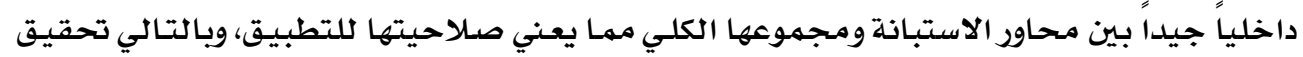

أهدافها.

بيانات الاتساق الداخلي بين محاور الدراسة والمجموع الكلي

\begin{tabular}{|c|c|}
\hline معامل ارتباط بيرسون & المحاور \\
\hline $.701 * *$ & المحور الأول: العوامل المرتبطة بالعمال (rاعبارة) \\
\hline $.618 * *$ & المحور الثاني: عوامل المرتبطة بالإدارة والإشراف (rاعبارة) \\
\hline $.791 * *$ & المحور الثالث: العوامل المالية والمادية (9 اعبارة) \\
\hline
\end{tabular}


(ا) معاملات ارتباط درجات العبارة مع العوامل المرتبطة بالعمال

\begin{tabular}{|c|c|}
\hline معامل ارتباط بيرسون & العبارة \\
\hline .330 & 1- عدد العمال يِ المصنع \\
\hline $.740(* *)$ & r- الأجر الشهري للعمال \\
\hline $.680(* *)$ & r- خبرة العمال \\
\hline $.603(* *)$ & ع- ـ وقت العمل الإضـاِِ \\
\hline $.438(* *)$ & 0- تغيير العمال داخل خط الإنتاج \\
\hline .232 & 7- عدد العمال الذين تنتهي خدمتهم سنويا \\
\hline $.457(* *)$ & V- نسبة غياب العمال ل \\
\hline $.513(* *)$ & 1- نوعية مستوى المهارة \\
\hline. $.368(*)$ & 9- - مستوى المنتج النهائي \\
\hline. $.518(* *)$ & • 1- نوع الآلات المستخدمة من حيث جودتها. \\
\hline $.502(* *)$ & 11- الوعي الصناعي \\
\hline .260 & بالخبر ات العملية ِِِ خطوات التشغيل \\
\hline
\end{tabular}

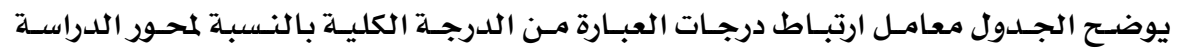

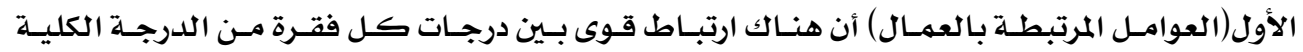

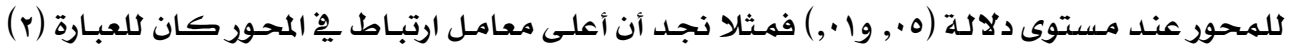

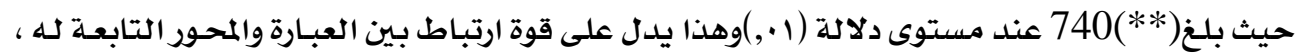

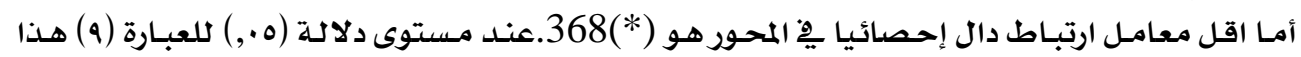

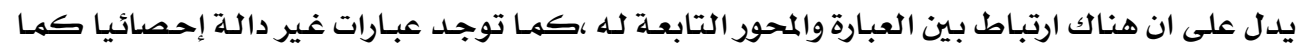

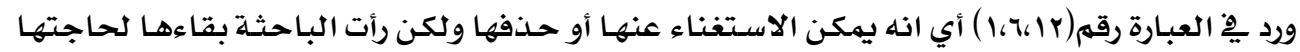
.

\section{هماهلات ارتباط درجات العبارة هم همبموع درجة المور الثاني}

عوامل المرتبطة بالإدارة والإشراف

\begin{tabular}{|c|c|}
\hline معامل الارتباط & العبارة - العبار \\
\hline $.589(* *)$ & إتباع أسـاليب الإحلال والتجديد \\
\hline $.523(* *)$ & الأسـلوب المتبـع ِِ الإشـراف \\
\hline $.529(* *)$ & إتباع أسـاليب الصيانة الوقائية \\
\hline $.698(* *)$ & نظام إنتاج (بالقطعة أو بالطلب) \\
\hline $.778(* *)$ & رصد معدلات أداء الأعمال والأنشطة \\
\hline $.505(* *)$ & منـافذ وقنوات التوزيـع \\
\hline $.723(* *)$ & التدريب والإرشـاد \\
\hline $.686(* *)$ & نوع الخـامـة المستخلدمـة \\
\hline $.633(* *)$ & التخطيط المسبق قبل الإنتاج \\
\hline $.679(* *)$ & الاستعانة بـالأبحاث العلميلة والأكاديمية \\
\hline $.652(* *)$ & قوانين حماية المنتجات الوطنية \\
\hline $.703(* *)$ & الخبر ات لدى مـراقبى الإنتاج \\
\hline
\end{tabular}




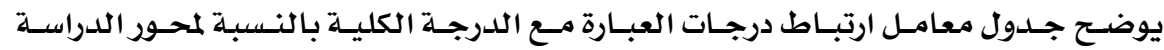

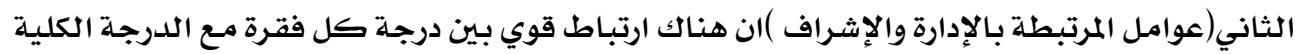

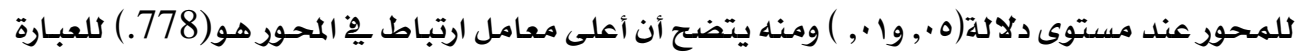

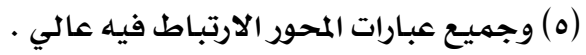

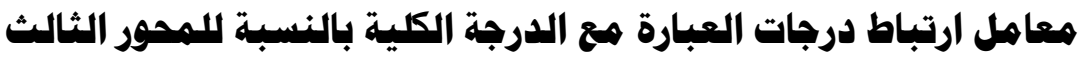
(المحور الثالث : العوامل المالية والمادية)

\begin{tabular}{|c|c|}
\hline معامل الارتباط & 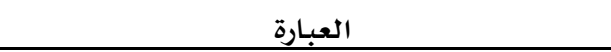 \\
\hline $.471(* *)$ & هيكل التمويل \\
\hline $.585(* *)$ & نفقات التشغيل \\
\hline $.534(* *)$ & الرقابة المالية \\
\hline $.565(* *)$ & نسبة المبيعات \\
\hline $.731(* *)$ & ارتفاع تكاليف الشحن والنقل \\
\hline $.705(* *)$ & زيـادة تكلفة المواد الخام \\
\hline $.667(* *)$ & ارتفاع نسبة التلف ِِِ المنتجات \\
\hline $.444(* *)$ & ارتفاع أجور العاملين \\
\hline $.624(* *)$ & زيادة المخزون من الخامات \\
\hline $.655(* *)$ & زيـادة ِِّ أسعار استيراد المواد الخام \\
\hline $572(* *)$ & ضعف الإدارة المالية \\
\hline $.735(* *)$ & ضعف إدارة التسويق \\
\hline $.656(* *)$ & ضعف إدارة التمويل \\
\hline $.628(* *)$ & 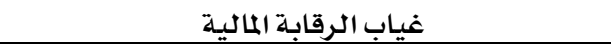 \\
\hline $.417(*)$ & العلاقات مع البنوك المختلفة \\
\hline $.441(* *)$ & تنسيق العلاقة مـع الأسواق المالية والوسطاء الماليون \\
\hline $.577(* *)$ & تغيير خط الإنتاج \\
\hline $.531(* *)$ & أعطال الماكينات \\
\hline $.478(* *)$ & المساحة المخصصة للتشغيل \\
\hline
\end{tabular}

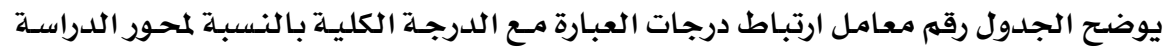

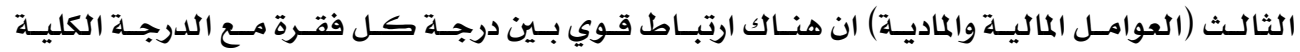

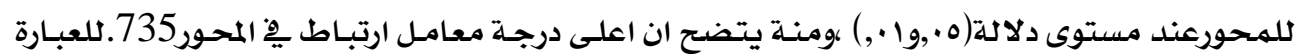

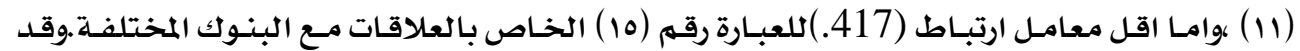

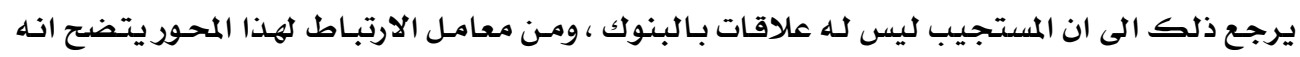

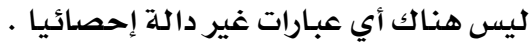




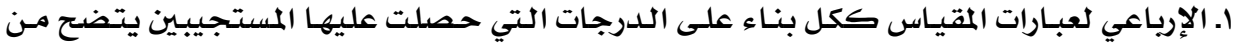

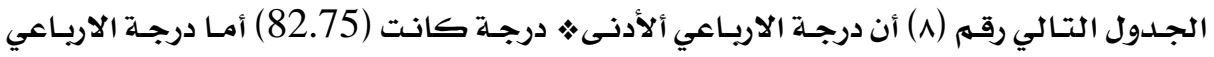

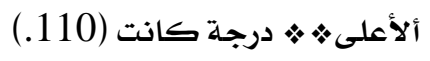

\begin{tabular}{||l|l|l|}
\hline \multicolumn{3}{|c|}{ Statistics } \\
\hline \hline \multirow{2}{*}{ tott } & Valid & 34 \\
\cline { 2 - 4 } & Missing & 0 \\
\hline Mean & 94.3235 \\
\hline Std. Deviation & 18.37112 \\
\hline Percentiles & 25 & 82.7500 \\
\cline { 2 - 3 } & 50 & 95.0000 \\
\cline { 2 - 3 } & 75 & 110.0000 \\
\hline \hline
\end{tabular}

ثانيا تصنيف المجموعات لعبارات المقياس ككل : تم تصنيف درجات المستجيبات إلى مجموعتين

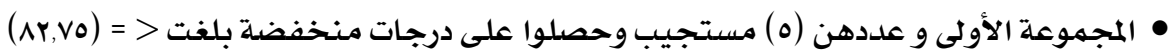

• المجموعة الثانية و عددهن (^) مستجيب وحصلوا على درجات مرتفعة بلغت => ( • (11). 


\begin{tabular}{|c|c|c|c|c|c|}
\hline الدلالة & \begin{tabular}{|c|} 
قيمة منانوتني \\
U
\end{tabular} & 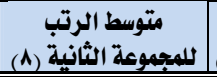 & 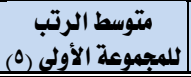 & العبارات & $A$ \\
\hline \multicolumn{6}{|c|}{ الحمور الأول : العواهل المرتبطة بالعمال } \\
\hline $002 \mathrm{a}$ & 10.000 & 5.75 & 9.00 & عدد العمال في المصنع & -1 \\
\hline $.171 \mathrm{a}$ & 1.500 & 4.69 & 10.70 & | الأجر الشهري للعمال & $\mathrm{r}$ \\
\hline $.003 \mathrm{a}$ & 1.500 & 4.69 & 10.70 & | - مخبرة العمال & 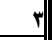 \\
\hline $.003 \mathrm{a}$ & 16.000 & 6.50 & 7.80 & 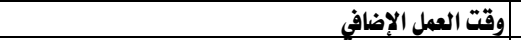 & 4 \\
\hline $.622 \mathrm{a}$ & 12.500 & 6.06 & 8.50 & | تفيير العمال داخل خط الإتتاج & $d$ \\
\hline $.284 \mathrm{a}$ & 13.000 & 6.13 & 8.40 & | علد العمال الذيز تنتهي خدمتهم سنويا & 7 \\
\hline $.354 \mathrm{a}$ & 4.500 & 4.81 & 5.06 & 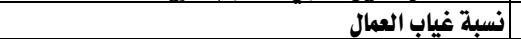 & $\mathrm{v}$ \\
\hline $.019 \mathrm{a}$ & 2.500 & 5.81 & 8.90 & | ل أوعية مستوى المهارة & $\mathrm{A}$ \\
\hline $.006 \mathrm{a}$ & 10.500 & 5.44 & 9.50 & | - مستوى المنتج النهائي & 9 \\
\hline $.171 \mathrm{a}$ & 7.500 & 5.00 & 10.20 & | نوع الآلات المستخدمة من حيث جودتها & 1. \\
\hline $.065 \mathrm{a}$ & 4.000 & & & | - الوعي الصناعي & 11) \\
\hline $.019 \mathrm{a}$ & 9.000 & 5.63 & 9.20 & | الخبرات العملية في خطوات التشفيل & iv \\
\hline \multicolumn{6}{|c|}{ المحور الثاني : عوأهل المرتبطة بالإدارة والإشراف } \\
\hline $.127 \mathrm{a}$ & 2.500 & 4.81 & 10.50 & | إتباع أساليب الإحلال والتجديد & it \\
\hline $.006 \mathrm{a}$ & 8.500 & 5.56 & 9.30 & الأسلوب التببع في الإشراف & $1 \varepsilon$ \\
\hline $.093 \mathrm{a}$ & 6.500 & 5.31 & 9.70 & إتباع أساليب الصيانة الوقائية & 10. \\
\hline $.045 \mathrm{a}$ & 3.000 & 4.88 & 10.40 & |نظام إتتاج (بالقطعة أو بالطلب) & 17. \\
\hline $.011 \mathrm{a}$ & 5.500 & 5.19 & 9.90 & | منافذ وقنوات التوزيع & A \\
\hline .003a & 2.000 & 5.06 & 10.60 & | التدريب والإرشاد & 19 \\
\hline $.030 \mathrm{a}$ & 4.000 & 4.81 & 10.20 & | نوع الخامة المستخدمة & r. \\
\hline $.006 \mathrm{a}$ & 6.500 & 5.31 & 9.70 & التخطيط المببق قبل الإتتاج & $\mathrm{ru}$ \\
\hline $.019 \mathrm{a}$ & 4.500 & 5.06 & 10.10 & الاستعانة بالأبحاث العلمية والأكاديمية & $r r$ \\
\hline $.045 \mathrm{a}$ & 4.500 & 5.00 & 10.20 & |قواذين حماية المنتجات الوطنية & $r$ \\
\hline $.019 \mathrm{a}$ & 2.500 & 4.81 & 10.50 & | الخبرات للدى مراقبي الإتتاج & rq \\
\hline \multicolumn{6}{|c|}{ الححور الثالث : العوأهل المالية والمادية } \\
\hline $.006 \mathrm{a}$ & 10.000 & 5.75 & 9.00 & - ميكل التمويل & ro \\
\hline $.171 \mathrm{a}$ & 5.000 & 5.13 & 10.00 & |نفقات التشفيل & $r 7$ \\
\hline $.030 \mathrm{a}$ & 9.500 & 5.69 & 9.10 & الرقابة المالية & $r v$ \\
\hline $.127 \mathrm{a}$ & 4.000 & 5.00 & 10.20 & |ن انسبة المبيعات & $\mathrm{rA}$ \\
\hline $.019 \mathrm{a}$ & 2.500 & 4.81 & 10.50 & | ارتفاع تكاليف الشحن والنقل & ra \\
\hline $.006 \mathrm{a}$ & 5.000 & 5.13 & 10.00 & | زيادة تكلفة المواد الخام & $r$. \\
\hline $.030 \mathrm{a}$ & 6.500 & 5.31 & 9.70 & | ارتقاع نسبة التلف في المتتجات & ril \\
\hline .045a & 7.500 & 5.44 & 9.50 & | ارتفاع أجور العاملين & rr \\
\hline .065 & 6.500 & 5.31 & 9.70 & إل إيادة المخزون من الخامات & $r$ \\
\hline .045a & 7.000 & 5.38 & 9.60 & | زيادة في أسعار استيراد المواد الخام & re \\
\hline $.065 \mathrm{a}$ & 6.500 & 5.31 & 9.70 & | ضعف الإدارة المالية & ro \\
\hline $.045 \mathrm{a}$ & 3.500 & 4.94 & 10.30 & | ضعف إدارة التسويق & rq \\
\hline $.011 \mathrm{a}$ & 6.500 & 5.31 & 9.70 & | ضعف إدارة التمويل & $r v$ \\
\hline $.045 \mathrm{a}$ & 2.500 & 4.81 & 10.50 & |غياب الرقابة المالية & $\mathrm{ra}$ \\
\hline $.006 \mathrm{a}$ & 12.500 & 4.81 & 8.50 & | العلاقات مع البنوك المختلفة & ra \\
\hline $.284 \mathrm{a}$ & 7.500 & 5.44 & 9.50 & |تنسيق العلاقة مع الأسواق المالية والوسطاء الماليون & 细 \\
\hline $011 \mathrm{a}$ & 3.000 & 4.81 & 10.50 & | تفيير خط الإتتاج & छा \\
\hline $.127 \mathrm{a}$ & 9.000 & 5.63 & 9.20 & | أعطال الماكينات & $\varepsilon r$ \\
\hline. $.002 \mathrm{a}$ & .500 & 4.56 & 10.90 & | المساحة المخصصة للتشفيل & st \\
\hline
\end{tabular}


حساب الإرباعيات لكل محور من محاور المقياس الأربعة

\begin{tabular}{|c|c|c|c|c|c|}
\hline \multicolumn{3}{|c|}{ 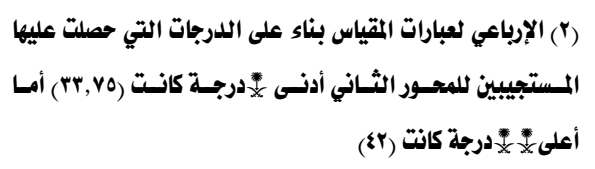 } & \multicolumn{3}{|c|}{ 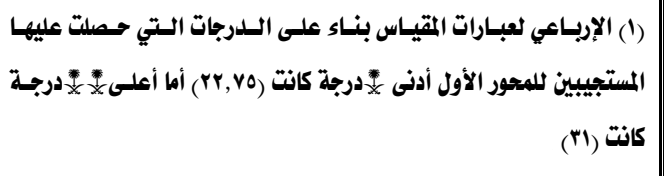 } \\
\hline \multicolumn{3}{|c|}{ Statistics } & \multicolumn{3}{|c|}{ Statistics } \\
\hline \multicolumn{3}{|c|}{ total2 } & \multicolumn{3}{|c|}{ clss2 } \\
\hline \multirow[t]{2}{*}{$\mathrm{N}$} & 34 & Valid & \multirow[t]{2}{*}{$\mathrm{N}$} & 34 & Valid \\
\hline & 0 & Missing & & 0 & Missing \\
\hline \multirow[t]{3}{*}{ Percentiles } & 33.7500 & 25 & \multirow[t]{3}{*}{ Percentiles } & 22.7500 & 25 \\
\hline & 37.5000 & 50 & & 26.0000 & 50 \\
\hline & 42.0000 & 75 & & 31.0000 & 75 \\
\hline & & & \multicolumn{3}{|c|}{ 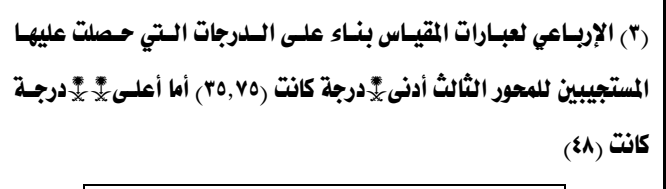 } \\
\hline & & & \multicolumn{3}{|c|}{ Statistics } \\
\hline & & & \multirow[t]{2}{*}{$\mathrm{N}$} & Valid & 34 \\
\hline & & & & Missing & 3 \\
\hline & & & \multirow[t]{3}{*}{ Percentiles } & 25 & 35.7500 \\
\hline & & & & 50 & 42.0000 \\
\hline & & & & 75 & 48.0000 \\
\hline
\end{tabular}

تصنيف المجموعات لعبارات المقياس للمحور الأول : تم تصنيف درجات المستجيبات إلى مجموعتين:

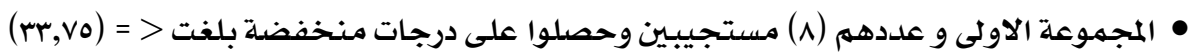

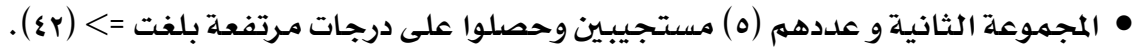
تصنيف المجموعات لعبارات المقياس للمحور الثاني : تم تصنيف درجات المستجيبيـين إلى مجمهوعتين:

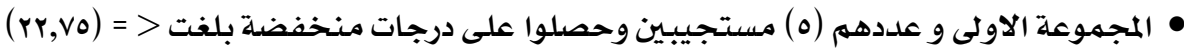

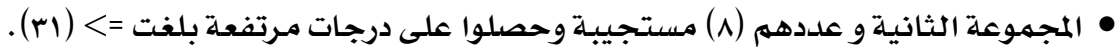
تصنيف المجموعات لعبارات المقياس للمحور الأول : تم تصنيف درجات المستجيبات إلى مجموعتين:

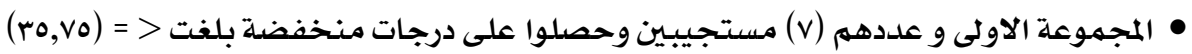

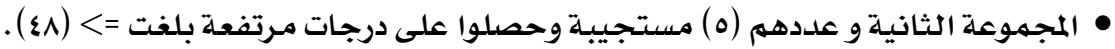




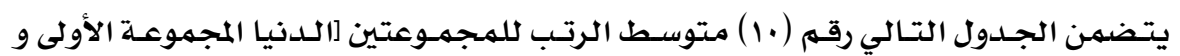

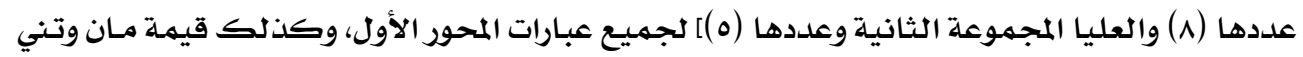

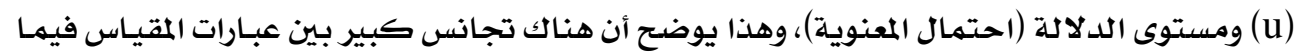

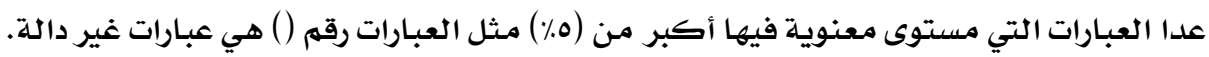

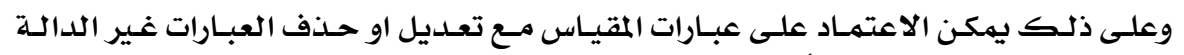

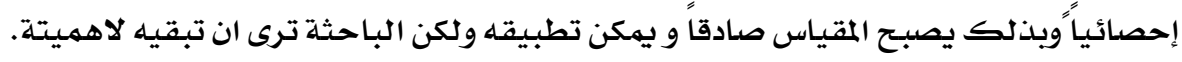

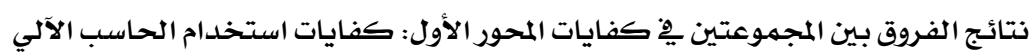

باستخدام مـان وتني جدول (1.)

\begin{tabular}{|c|c|c|c|c|c|}
\hline مستوى الدلالة & $\begin{array}{c}\text { قيمة منانوتني } \\
\text { قمس U }\end{array}$ & 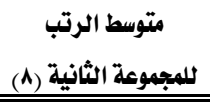 & 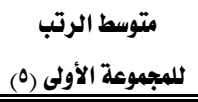 & 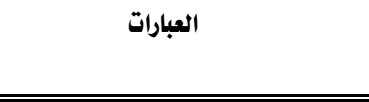 & 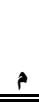 \\
\hline \multicolumn{6}{|c|}{ المهور الأول: العواهل المرتبطة بالعمال } \\
\hline $171 \mathrm{a}$ & 10.000 & 5.75 & 9.00 & عدد العمال في المصنع & 1 \\
\hline $003 a$ & 1.500 & 4.69 & 10.70 & الأجر الشهري للعمال & $r$ \\
\hline $.003 \mathrm{a}$ & 1.500 & 4.69 & 10.70 & خخبرة العمال & $r$ \\
\hline $.622 \mathrm{a}$ & 16.000 & 6.50 & 7.80 & وقت العمل الإضافي & $\varepsilon$ \\
\hline $.284 \mathrm{a}$ & 12.500 & 6.06 & 8.50 & تفيير العمال داخل خط الإتتاج & $\circ$ \\
\hline $.354 \mathrm{a}$ & 13.000 & 6.13 & 8.40 & عدد العمال الذين تنتهي خدمتهم سنويا & 9 \\
\hline $.019 \mathrm{a}$ & 4.500 & 5.06 & 10.10 & نسبة غياب العمال & $r$ \\
\hline $.006 \mathrm{a}$ & 2.500 & 4.81 & 10.50 & نوعية مستوى المهارة & $\wedge$ \\
\hline $.171 \mathrm{a}$ & 10.500 & 5.81 & 8.90 & مستوى المنتج النهائي & 9 \\
\hline $.065 \mathrm{a}$ & 7.500 & 5.44 & 9.50 & نوع الآلات المستخدمة من حيث جودتها & 1. \\
\hline $.019 \mathrm{a}$ & 4.000 & 5.00 & 10.20 & الوعي الصناعي & 11 \\
\hline $.127 \mathrm{a}$ & 9.000 & 5.63 & 9.20 & الخبرات العملية في خطوات التشفيل & ir \\
\hline
\end{tabular}

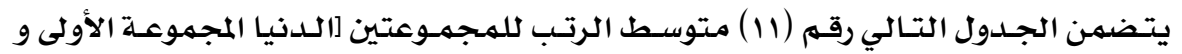

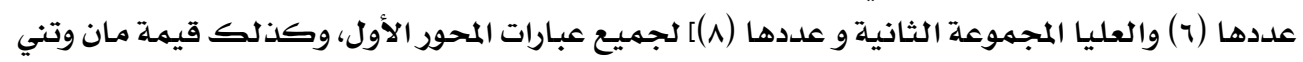

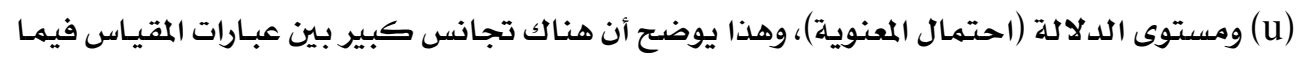

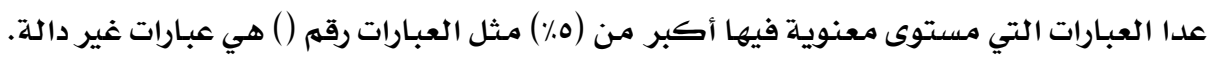




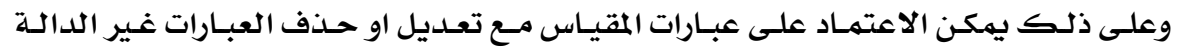

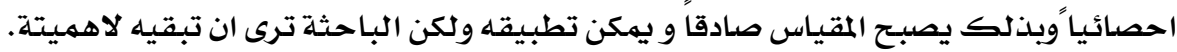

\begin{tabular}{|c|c|c|c|c|c|}
\hline \begin{tabular}{|l} 
الدلالة \\
\end{tabular} & $\begin{array}{l}\text { قيمة منانوتني } \\
\text { قس U }\end{array}$ & 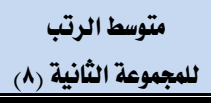 & 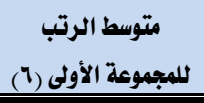 & 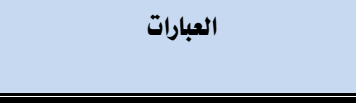 & P \\
\hline \multicolumn{6}{|c|}{ المحور الثاني : عواهل هرتبطة بالإدارة والإشراف } \\
\hline $.013 \mathrm{a}$ & 5.000 & 5.13 & 10.67 & إتباع أساليب الإحلال والتجديد & ir \\
\hline $.029 \mathrm{a}$ & 7.000 & 5.38 & 10.33 & الأسلوب المتبع في الإشراف & is \\
\hline $.020 \mathrm{a}$ & 6.000 & 5.25 & 10.50 & إتباع أساليب الصيانة الوقائية & 10 \\
\hline $.003 \mathrm{a}$ & 2.000 & 4.75 & 11.17 & نظام إتتاج (بالقطعة أو بالطلب) & 17 \\
\hline $.001 \mathrm{a}$ & .000 & 4.50 & 11.50 & رصد معدلات أداء الأعمال والأنشطة & iv \\
\hline $.020 \mathrm{a}$ & 6.000 & 5.25 & 10.50 & منافذ وقنوات التوزيع & in \\
\hline $.001 \mathrm{a}$ & .000 & 4.50 & 11.50 & التدريب والإرشاد & 19 \\
\hline $.001 \mathrm{a}$ & 1.500 & 4.69 & 11.25 & نوع الخامة المستخدمة & r. \\
\hline $.003 \mathrm{a}$ & 2.000 & 4.75 & 11.17 & التخطيط المسبق قبل الإتتاج & r \\
\hline $.001 \mathrm{a}$ & .000 & 4.50 & 11.50 & الاستعانة بالأبحاث العلمية والأكاديمية & r \\
\hline $001 \mathrm{a}$ & .500 & 4.56 & 11.42 & قوانين حماية المنتجات الوطنية & re \\
\hline $.005 \mathrm{a}$ & 3.000 & 4.88 & 11.00 & الخبرات للدى مراقبي الإتتاج & rq \\
\hline
\end{tabular}

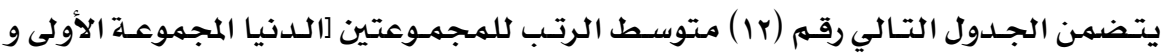

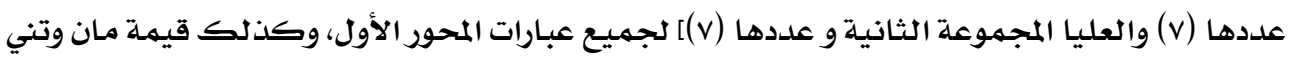
(u)

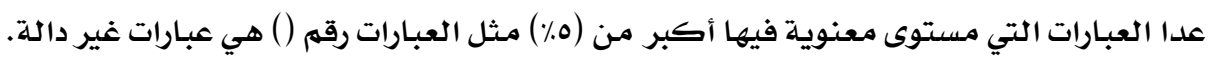

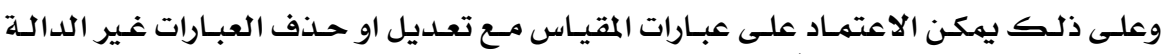

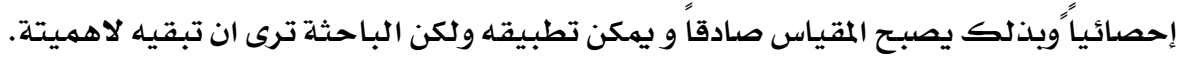




\begin{tabular}{|c|c|c|c|c|c|}
\hline توى الدلالة & $\begin{array}{l}\text { قيمة منانوتني } \\
\text { Uمس U }\end{array}$ & 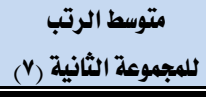 & 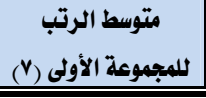 & العبارات & 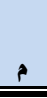 \\
\hline \multicolumn{6}{|c|}{ لمور الثالث : العهاهل المالية والمادية } \\
\hline $.209 \mathrm{a}$ & 14.000 & 6.00 & 9.00 & هيكل التمويل & ro \\
\hline $.038 \mathrm{a}$ & 8.500 & 5.21 & 9.79 & نفقات التشفيل & rq \\
\hline $.053 \mathrm{a}$ & 9.000 & 5.29 & 9.71 & الرقابة المالية & rr \\
\hline $.017 \mathrm{a}$ & 6.500 & 4.93 & 10.07 & نسبة المبيعات & ra \\
\hline $.001 \mathrm{a}$ & .000 & 4.00 & 11.00 & ارتفاع تكاليف الشحز والنقل & ra \\
\hline $.001 \mathrm{a}$ & 1.000 & 4.14 & 10.86 & زيادة تكلفة المواد الخام & r. \\
\hline $.002 \mathrm{a}$ & 2.000 & 4.29 & 10.71 & ارتفاع نسبة التلف في المنتجات & ri \\
\hline $038 \mathrm{a}$ & 8.500 & 5.21 & 9.79 & ارتفاع أجور العاملين & rr \\
\hline $.038 \mathrm{a}$ & 1.500 & 4.21 & 10.79 & زيادة المخزون من الخامات & rr \\
\hline $.004 \mathrm{a}$ & 3.000 & 4.43 & 10.57 & زيادة في أسعار استيراد المواد الخام & $r \varepsilon$ \\
\hline $.001 \mathrm{a}$ & 1.000 & 4.14 & 10.86 & ضعف الإدارة المالية & ro \\
\hline $.001 \mathrm{a}$ & 000 & 4.00 & 11.00 & ضعف إدارة التسويق & m \\
\hline $.001 \mathrm{a}$ & .000 & 4.00 & 11.00 & ضعف إدارة التهويل & rr \\
\hline $.011 \mathrm{a}$ & 5.500 & 4.79 & 10.21 & غياب الرقابة المالية & ra \\
\hline $.017 \mathrm{a}$ & 6.000 & 4.86 & 10.14 & العلاقات مع البنوك المختلفة & ra \\
\hline $.038 \mathrm{a}$ & 8.000 & 5.14 & 9.86 & تنسيق العلاقة مع الأسواق المالية والوسطاء الماليوذ & $\xi \cdot$ \\
\hline $.004 \mathrm{a}$ & 3.000 & 4.43 & 10.57 & تفيير خط الإنتاج & $\$ 1$ \\
\hline $.017 \mathrm{a}$ & 6.500 & 4.93 & 10.07 & أعطال الماكينات & $\xi r$ \\
\hline $.004 \mathrm{a}$ & 3.000 & 4.43 & 10.57 & المساحة المخصصة للتشفيل & str \\
\hline
\end{tabular}

\section{ثانيًا- قيم ودلالة هؤشرات ثبات الاستبانة :}

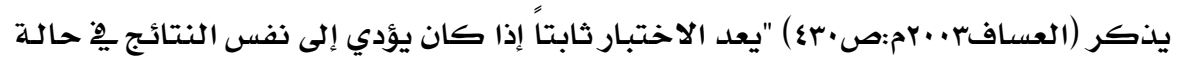

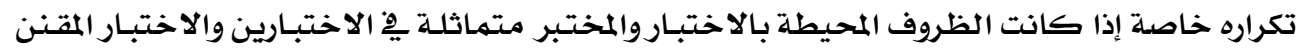

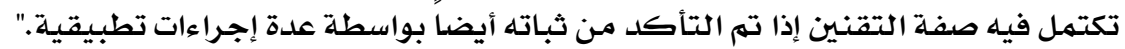

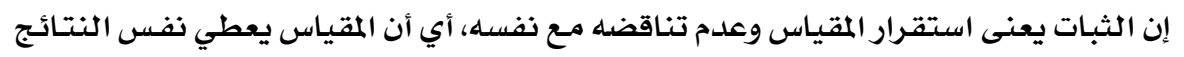

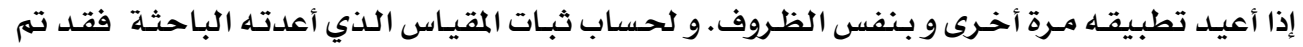

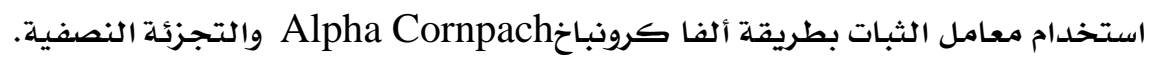

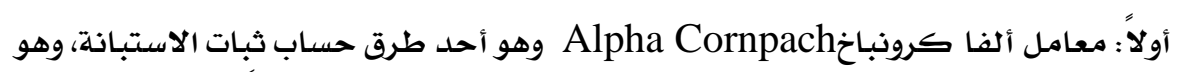

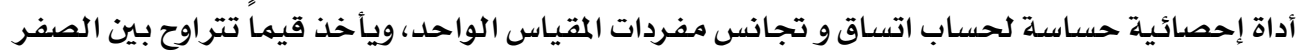


العوامل المؤثرة على الإنتاج ِِِ صناعة الملابس الجاهزة بملينة جلة

\begin{tabular}{|c|c|c|c|c|c|}
\hline معامل الفا & 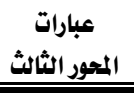 & معامل الفا & المحور الثاني & معامل الفا & $\begin{array}{c}\text { المحور الأول } \\
\end{array}$ \\
\hline .990 & .25 & .990 & .13 & .990 & .1 \\
\hline .990 & .26 & .990 & .14 & .990 & .2 \\
\hline .990 & .27 & .990 & .15 & .990 & .3 \\
\hline .990 & .28 & .990 & .16 & .990 & .4 \\
\hline .990 & .29 & .990 & .17 & .990 & .5 \\
\hline .990 & .30 & .990 & .18 & .990 & .6 \\
\hline .990 & .31 & .990 & .19 & .990 & .7 \\
\hline .990 & .32 & .990 & .20 & .990 & .8 \\
\hline .990 & .33 & .990 & .21 & .990 & .9 \\
\hline .990 & .34 & .990 & .22 & .990 & .10 \\
\hline .990 & .35 & .990 & .23 & .990 & .11 \\
\hline .990 & .36 & .990 & .24 & .990 & .12 \\
\hline .990 & .37 & & & & \\
\hline .990 & .38 & & & & \\
\hline .990 & .39 & & & & \\
\hline .990 & .40 & & & & \\
\hline .990 & .41 & & & & \\
\hline .990 & .42 & & & & \\
\hline .990 & .43 & & & & \\
\hline
\end{tabular}

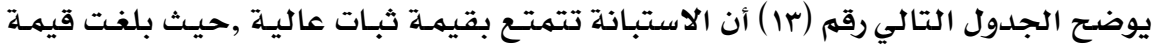

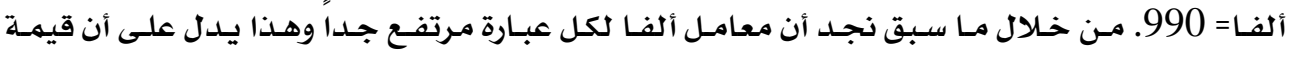

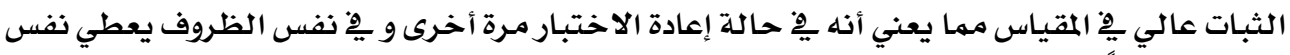
النتائج تقريبا.

جلدول (ri) قيمـة معامل الفا لجميع عبارات المقياس معاً

\begin{tabular}{|c|c|}
\hline معامل الظا & عدد العبارات \\
\hline 99. & $\varepsilon r$ \\
\hline
\end{tabular}

ثانيًا: همعامل الثبات بالتجزئة النصفية:

جدول(ع) ) قيمة معامل الثبات بالتجزئة النصفية لعبارات المقياس

\begin{tabular}{|c|c|c|c|}
\hline قيمة معامل الثبات & في المجموعة الثانية & قيمة معامل الثبات & في المجموعة العبارات \\
\hline .921 & $21 b$ & 908 & $22 \mathrm{a}$ \\
\hline
\end{tabular}

Alpha for part $1=.921$

Alpha for part 2 $=.908$ 
ومها سبق نجد أن قيهـة معامـل ألفـا بالتجزئـة النصفية لعبـارات المقيـاس للهـجموعـة الأولى أقل من قيمهة معامل الفا بالتجزئة النصفية لعبارات المقيـاس للمهجموعة الثانية. :

مها سبق يمكن استخلاص أن عبارات المقيـاس يهكن الاعتماد عليها لتحقيـق الهدف الـذي و

ضعت لأجلـه امـا العبـارات منخفضشة الارتبـاط يهكن إعـادة صـياغتها و مـن ثم إعـادة تطبيق الاستبيـان

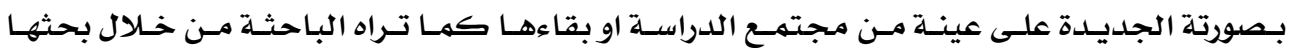
لحاجتها لتلك العبارات المنخخضشة الارتباط. 


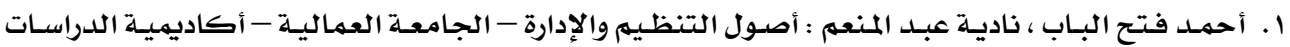

$$
\text { المتخصصة - القاهرة - r... }
$$

r. أحمد حسنى خطاب نجم الدين : الصعوبات التي تواجه خطوط إنتاج مـصانع الملابس الجـاهزة ذات الإنتاج غير النمطي ووضع بعض الحلول المقترحة باستخدام الحاسوب - رسالة ماجستير - كلية الاقتصاد المنزلي - جامعة المنوفية - -

م. تريز بطشون: واقع الرقابة على صناعية الجودة الإنتاج فِ الشركات الأردنية - دراسـة تطبيقيـة وتحليليـة -

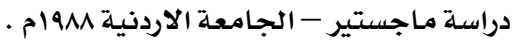

ع. جان نورا ستينة ، أمل القرن العشرين الكبير ، ترجمة عبد الحميد الكاتب ، بيروت ،منشورات عويدات، ـ 1977

ه. العلي وجيه عبد الرسول ، الإنتاجية ، مفهومها ، قياسها ، العوامل المؤثرة فيها ، دار. الطليعـة ، بيروت ، بر19

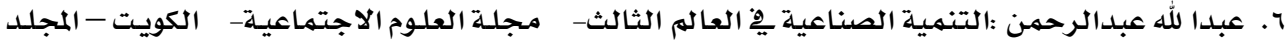

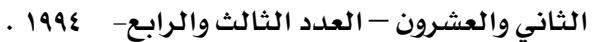

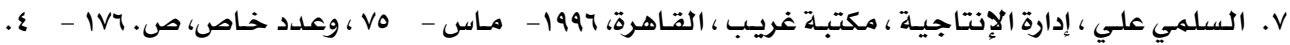

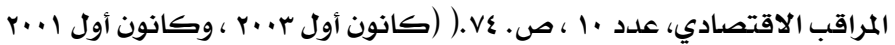

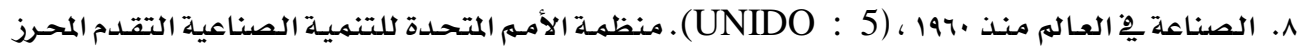

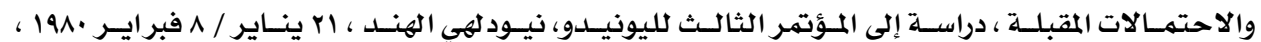

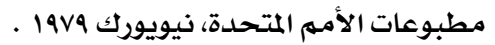

9. محمد كامل النحاس : علهم النفس فى الصناعة تأليف نورمان مايير ، ترجمة محمد عمادالدين إسماعيل

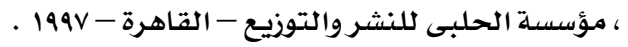

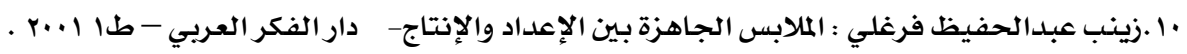

المراجع الأجنبية :

1. 1- ILO : Methods of Labor Productivity, Studies and Reports , New Series , -6 No 18 , Geneva , 1951

2. 2- Peter Marc and Pot Franck : Integral organizational innovation in ' the Dutch clothing industry: the myth of new production systems

Cohen Moreis A: A production line that balances itself - New-

3. direction in operations management, institute for operations research and the management sciences, MD, U.S.A. 1996

4. المبادئ العامة لحلقات ضبط الجودة، كاورو إيشيكاو ا، الطبعة العربية http://samehar.wordpress.com/2009/05/25/230509 